\title{
ANÁLISE DO DESEMPENHO TÉRMICO DE UM SISTEMA DE AQUECIMENTO SOLAR DE BAIXO CUSTO NA CIDADE DE MOSSORÓ (RN)
}

\author{
M. I. S. GUERRA e F. K. O. M. VARELLA
Departamento de Ciências Ambientais e Tecnológicas (DCAT) - Universidade Federal Rural do Semiárido
fkv@ufersa.edu.br \\ Artigo submetido em fevereiro/2013 e aceito em março/2014 \\ DOI: $10.15628 /$ holos.2014.1266
}

\section{RESUMO}

O presente trabalho estuda a possibilidade de instalação e utilização de um Sistema de Aquecimento Solar de Água Não Convencional e de Baixo Custo (SASncbc) na cidade de Mossoró/RN. Para isso, foi analisado o desempenho térmico de cada elemento que compõe o sistema de aquecimento solar separadamente, a fim de analisar o comportamento que os mesmos apresentaram na cidade em estudo. O SASncbc é composto por um coletor solar plano e um reservatório térmico, e o funcionamento desse sistema é realizado através do regime de convecção natural, também conhecido como termossifão. Foi determinado que o coletor solar não convencional e de baixo custo confeccionado apresenta boas temperaturas de saída, apesar do seu baixo rendimento, entretanto, não ser adequado para ser utilizado na cidade de Mossoró/RN, pois atingiu ou ultrapassou, em alguns momentos da pesquisa, os níveis críticos de temperatura para início da degradação térmica de alguns dos materiais utilizados. Por outro lado, o reservatório térmico não convencional e de baixo custo construído apresentou bons resultados, podendo inclusive ser utilizado em outros sistemas de aquecimento de água alternativos ou não convencionais

PALAVRAS-CHAVE: Sistema de aquecimento solar, Baixo custo, Coletor solar, Reservatório térmico, Energia Solar

\section{THERMAL PERFORMANCE'S ANALYSIS OF A LOW COST SOLAR HEATING SYSTEM IN THE CITY OF MOSSORÓ (RN)}

\begin{abstract}
This paper studies the possibility of installing and using a Low Coast Unconventional System of Water Heating (SASncbc) in the city of Mossoró/RN. For this, it was analyzed the thermal performance and the behavior of each element that makes up the system, which consists of a flat solar collector and a thermal reservoir. The operation of the system is accomplished through natural convection regime, also known as thermosyphon. It was determined that the SASncbc has achieved good output
\end{abstract}

temperatures, despite its low yield. However, it is not suitable for use in the city of Mossoró/RN, because in some moments it reached or exceeded the critical levels of temperature for the start of the system's thermal degradation of some of the materials used. Despite this, the thermal reservoir built has shown satisfactory results, and may also be used in other alternative or unconventional water heating systems.

KEYWORDS: Solar heating system. Low cost. Solar collector. Thermal reservoir. Solar energy. 


\section{INTRODUÇÃO}

A energia solar é fundamental para a vida na terra, e é uma fonte de energia que influencia em quase todas as outras fontes de energia, tais como hidráulica, biomassa e eólica. Por ser considerada uma fonte de energia não poluente, o que a torna ideal para a proteção ao meio ambiente, a energia proveniente do sol ainda pode ser considerada como uma fonte renovável, direta de luz e calor, existindo diferentes maneiras de aproveitá-la, seja de maneira ativa ou passiva. Com a finalidade de se obter um melhor aproveitamento dessa fonte de energia procurase aperfeiçoar os processos de utilização, aumentando a eficiência seja através da energia elétrica ou energia térmica.

Entre as formas de aproveitamento da energia solar, Melo (2008) apud Lopo (2010) afirma que atualmente as mais tradicionalmente utilizadas são o aquecimento de água e a geração de energia elétrica através da energia solar fotovoltaica.

Destas duas formas de aproveitamento da energia solar, a energia solar fotovoltaica é obtida através de uma tecnologia capaz de converter a energia solar em eletricidade através do uso do seu principal componente, o módulo fotovoltaico, que é constituído de material semicondutor e apresenta um elevado preço de aquisição. Por outro lado, a energia solar térmica de baixa temperatura é obtida a partir da utilização do sistema de aquecimento solar, que se trata de uma tecnologia que converte a energia solar em energia térmica, sendo mais aplicada no aquecimento de água. Os principais componentes desse sistema são os coletores solares e o reservatório térmico, que são bem menos onerosos do que os módulos fotovoltaicos, e apresentam maior difusão e utilização no Brasil. Além disso, o aquecedor solar de água possibilita a construção de componentes alternativos, que ajudam a reduzir os custos do sistema.

Mesmo com a facilidade de se encontrar os sistemas de aquecimento solar de água no mercado nacional, tais sistemas ainda possuem preços elevados, se tornando inacessíveis para uma parcela da população brasileira. Porém, visando propor a utilização de sistemas alternativos em substituição aos sistemas convencionais, ou seja, aqueles comercializados no mercado nacional, alguns tipos de sistemas de aquecimento solar de água de baixo custo foram desenvolvidos e estudados no país. Tal fato é extremamente positivo, pois se trata de uma alternativa mais acessível para parte da população que deseja usufruir dos benefícios de um sistema de aquecimento solar de água.

Apesar das diferentes características climáticas no Brasil, a média anual de irradiação solar global apresenta boa uniformidade, com médias anuais altas em todo o país. Os valores de irradiação solar global incidente em qualquer região do país variam de 4,2 a 6,7 kWh/m², e a região semiárida do nordeste brasileiro apresenta valores máximos de irradiação solar (PEREIRA et. al, 2006). Os números mostrados são superiores aos da maioria dos países da União Européia, como por exemplo, Alemanha, França e Espanha.

Entretanto, se por um lado os altos índices de insolação ao longo do ano favorecem o aproveitamento da energia solar, por outro, a instalação de sistemas não convencionais de aquecimento solar de água, ou seja, que utilizam em sua construção materiais de baixo custo, como os tubos de Policloreto de Vinilo (PVC), vão requerer observação constante. Tal fato é 
necessário, pois a susceptibilidade dos tubos de PVC atingem seu nível crítico e iniciam a sua degradação em uma temperatura em torno de 60ㄷ (LOPO, 2010).

Dentro desse contexto, o presente trabalho tem por objetivo analisar e determinar o desempenho térmico de um Sistema de Aquecimento Solar de Água Não Convencional e de Baixo Custo (SASncbc) instalado em uma região localizada no semiárido nordestino, mais precisamente, em Mossoró/RN.

\section{OS SISTEMAS DE AQUECIMENTO SOLAR DE ÁGUA NÃO CONVENCIONAIS NO BRASIL}

O principal objetivo da substituição dos materiais convencionais dos coletores solares industrializados por materiais não convencionais que necessitam de baixos investimentos está na redução dos custos de fabricação através da socialização do uso de sistemas de aquecimento de água, principalmente, para fins domésticos. Por esse motivo algumas instituições brasileiras têm pesquisado maneiras de desenvolver sistemas de aquecimento solar de água que sejam economicamente mais acessíveis, mas sem perder de forma significativa a eficiência do sistema.

Uma das vantagens do desenvolvimento do aquecimento solar de água utilizado materiais não convencionais, refere-se ao fato do mesmo poder ser utilizado por aqueles que não possuem elevada renda. Alguns sistemas já foram desenvolvidos em várias cidades do país, e cada um possui características particulares que contribuem para o aumento da eficiência do sistema na sua região.

Sendo assim, o presente item explanará os sistemas alternativos de maior destaque no país, bem como detalhará os sistemas de aquecimento solar de água não convencionais desenvolvidos na região nordeste, ou seja, na região do estudo proposto neste trabalho.

Sabe-se que os pioneiros no estudo do desempenho térmico de coletores solares utilizando materiais não convencionais surgiram na década de 50. Willer; Hottel (1959) apud Gomes (2010) e Bliss (1959) apud Gomes (2010) utilizaram coletores solares com tubos paralelos e tiveram resultados que serviram como base para outras pesquisas.

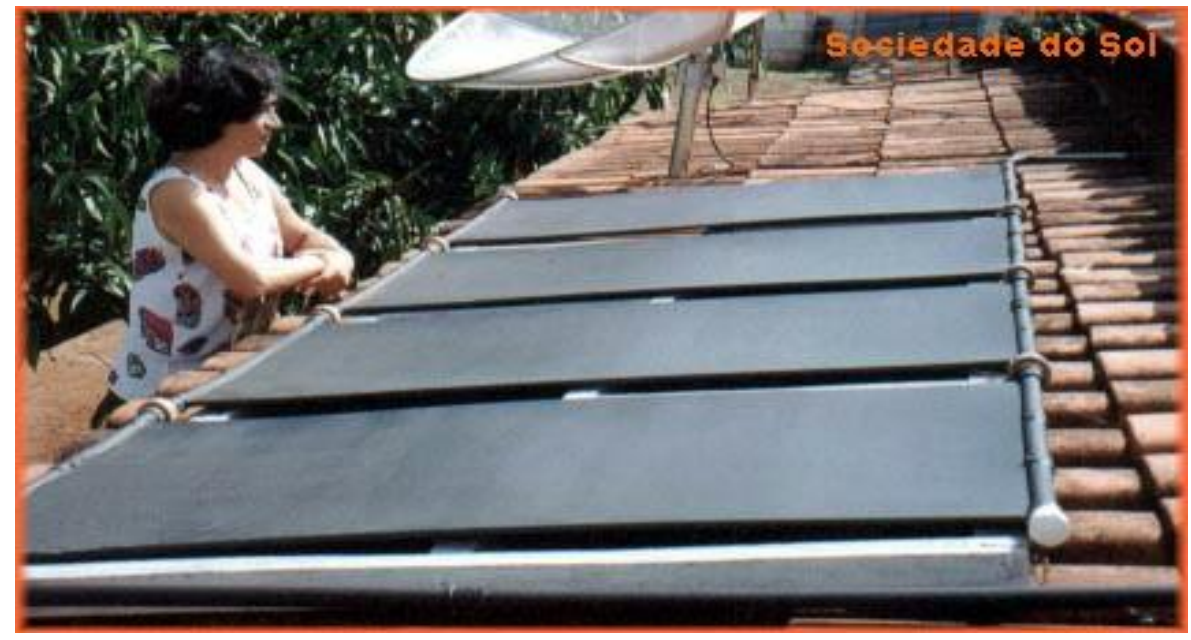

Figura 1 - Família beneficiada com um Aquecedor Solar de Baixo Custo (ASBC) de 400 litros Fonte: Sociedade do Sol (2003)

Após de mais de trinta anos, Rivera (1994) apud Gomes (2010) apresentou um trabalho sobre um coletor solar não convencional tubular e com múltiplas unidades absorvedoras de cloreto 
de polivinila (PVC). Em seguida, Lourenço (1997) apud Gomes (2010) desenvolveu um coletor com grade absorvedora composta por múltiplos tubos de alumínio, mas foi o coletor que usou com tubos absorvedores de PVC que apresentou uma maior viabilidade e capacidade de competição com os coletores convencionais. No mesmo ano, Matrawy; Farkas (1997) apud Gomes (2010) desenvolveram um estudo comparativo entre um coletor com duas placas paralelas, outro com tubos paralelos, e mais um com tubos em serpentina, verificando no final do estudo que o primeiro desses é o mais eficiente.

Foi apenas em 1999 que um dos coletores alternativos mais conhecidos e mais usados no Brasil foi desenvolvido, e sua aplicação pode ser vista na Figura 01.

O Aquecedor Solar de Baixo Custo (ASBC), mostrado na Figura 1, foi apresentado pelo Centro Incubador de Empresas Tecnológicas (CIETEC/SP) e criado pela Organização não governamental (ONG) Sociedade do Sol. Tal aquecedor trata-se de um sistema formado com três placas coletoras de $0,91 \mathrm{~m}^{2}$ de PVC interligadas e pintadas de preto sem cobertura e um reservatório de volume igual a 170 litros. Em cada placa coletora há um perfil modular de forro de PVC, com tubos de PVC acoplados as suas extremidades, funcionando em regime de termossifão. Esse aquecedor tem capacidade de atender uma família de quatro pessoas, e quando comparado a outros sistemas não convencionais, seus resultados são satisfatórios (VARELLA, 2004).

Em 2004, essa mesma ONG construiu um coletor solar utilizando garrafas PET e embalagens Tetra Pak ${ }^{1}$, que pode ser visualizado na Figura 2. O coletor solar desenvolvido era constituído por 80 garrafas PET e grades absorvedores, formado por oito tubos de PVC ligados em paralelo.

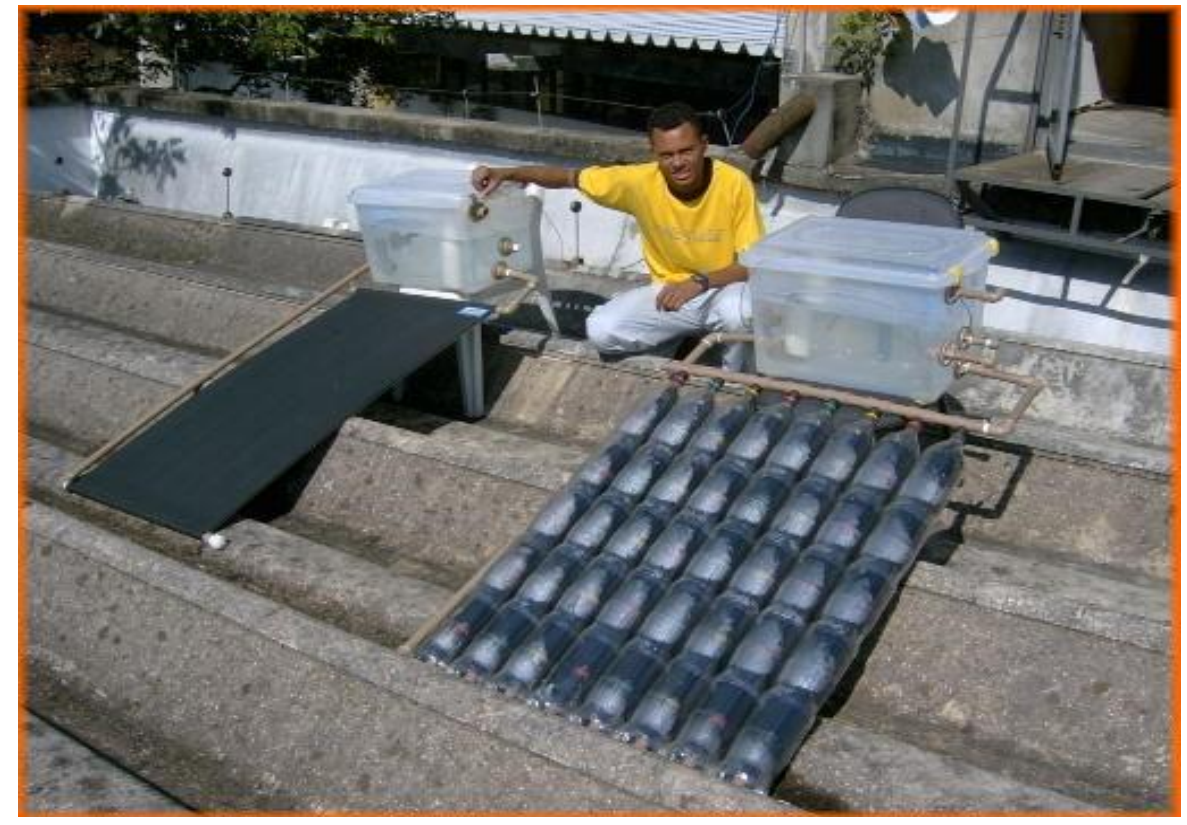

Figura 2 - ASBC construído com PVC (à esquerda) e com garrafa PET e Tetra Pak (à direita) Fonte: Sociedade do Sol (2003)

Seguindo a linha do desenvolvimento de sistemas de aquecimento solar de água não convencionais, o Laboratório de Energia Solar da Universidade Federal do Rio Grande do Norte

\footnotetext{
${ }^{1}$ Empresa multinacional que produz embalagens para diferentes produtos longa vida. Essas embalagens possuem seis camadas, na qual quatro delas são camadas de plástico, uma é de alumínio e a outra de papel. Juntas, essas camadas contribuem na proteção e conservação do alimento embalado. As embalagens também são conhecidas como embalagens longa vida.
} 
(LES/UFRN) vem se destacando no desenvolvimento de tais sistemas, e em seus mais de 25 anos de existência, possui uma quantidade significativa de trabalhos já estudados, desenvolvidos e analisados. A principal linha de pesquisa do LES/UFRN é o estudo, desenvolvimento e construção de coletores não convencionais.

Souza et al. (2008) possui uma lista de trabalhos desenvolvidos compostos por coletores solares e reservatórios térmicos não convencionais com resultados satisfatórios. Os coletores solares, por exemplo, já foram confeccionados à partir de tubos de PVC, garrafas PET e até mesmo latas de alumínio bebidas. Quanto aos reservatórios, esses já foram confeccionados com tambores de polietileno revestido por um cilindro de fibra de vidro com isolantes térmicos, como também de poliestireno expandido (EPS ou isopor) triturado, entre o reservatório e o revestimento.

Apesar dos diferentes materiais e das diversificadas formas desenvolvidas, todos os sistemas desenvolvidos no LES/UFRN apresentaram custos inferiores aos sistemas de aquecimento solares de água comerciais, consequentemente, barateando o custo de fabricação e ampliando a acessibilidade das famílias com menor renda. Um protótipo desenvolvido pelo LES, com seu coletor feito com garrafas PET e o reservatório revestido de fibra de vidro, está ilustrado na Figura 3.
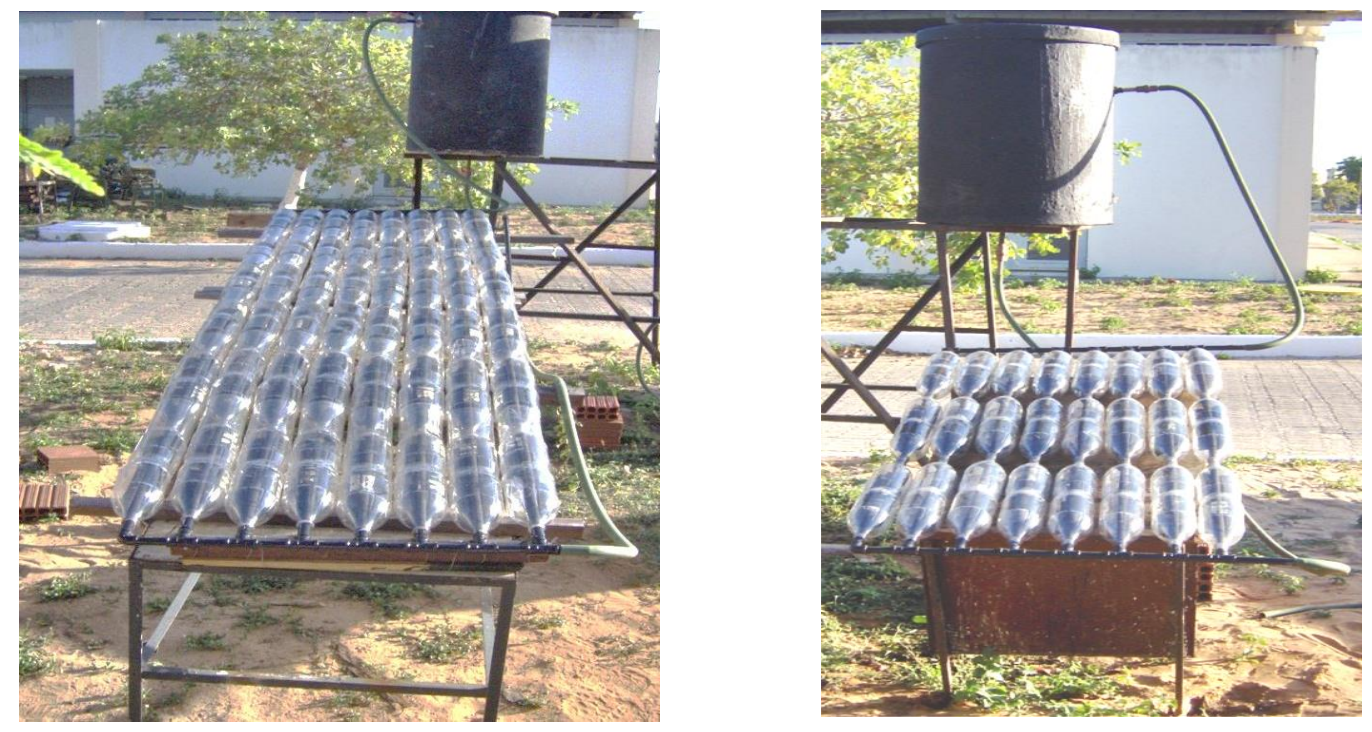

Figura 3 - Sistema não convencional utilizando garrafas PET desenvolvido pelo LES/UFRN Fonte: Santos (2007)

Leal (2008) apud Reis (2009) mostrou uma possível competição no custo/benefício de um coletor solar térmico para aquecimento de água, confeccionado com matérias recicláveis e de baixo custo, com os coletores solares industrializados. De acordo com Reis (2009), o coletor solar alternativo produzido por Leal (2008) era composto de tubos em PVC, caixas cartonadas Tetra Pak e garrafas PET pós-consumo.

Outro coletor construído por Reis (2009), com obtenção de resultados satisfatórios, possui cinco placas de forro de PVC de $10 \mathrm{~mm}$ de espessura, $200 \mathrm{~mm}$ de largura e $1.400 \mathrm{~mm}$ de comprimento, ou seja, uma área total de $1,40 \mathrm{~m}^{2}$.

No mesmo ano, Abreu (2009) confeccionou e, também obteve resultados satisfatórios, quando utilizou um sistema com a finalidade de um banho por pessoa para uma família de até quatro membros. O coletor não convencional desenvolvido por Abreu (2009) possuía cobertura transparente plana de 3,0 $\mathrm{mm}$ de espessura, chapa de alumínio de $0,5 \mathrm{~mm}$ ondulada com oito 
aletas, grade absorvedora formada por oito tubos de PVC com diâmetro externo de $20 \mathrm{~mm}$ e foram ligados em paralelos através de joelhos e conexões em " $\mathrm{T}$ " de mesmo material e diâmetro, além de isolante térmico constituído de raspa de pneu e uma caixa para o coletor, que foi construída com compensado de $15 \mathrm{~mm}$ de espessura.

Em 2010, Lopo (2010) estudou um sistema de aquecimento solar de água de baixo custo e dimensionado para o banho de uma família com quatro pessoas. O coletor não convencional foi construído a partir de tubos de PVC ligados em paralelo através de conexões, formando a grande absorvedora. Foram estudadas mais de cinco configurações foram estudadas tanto para o reservatório térmico de 150 litros, como para o reservatório térmico de 200 litros, ambos com a finalidade de armazenar a água aquecida pelo sistema e quatro destas configurações são mostradas na Figura 4. Além disso, Lopo (2010) avaliou a contribuição das aletas absorvedoras que foram fabricadas com latas de bebidas acopladas aos tubos absorvedores.

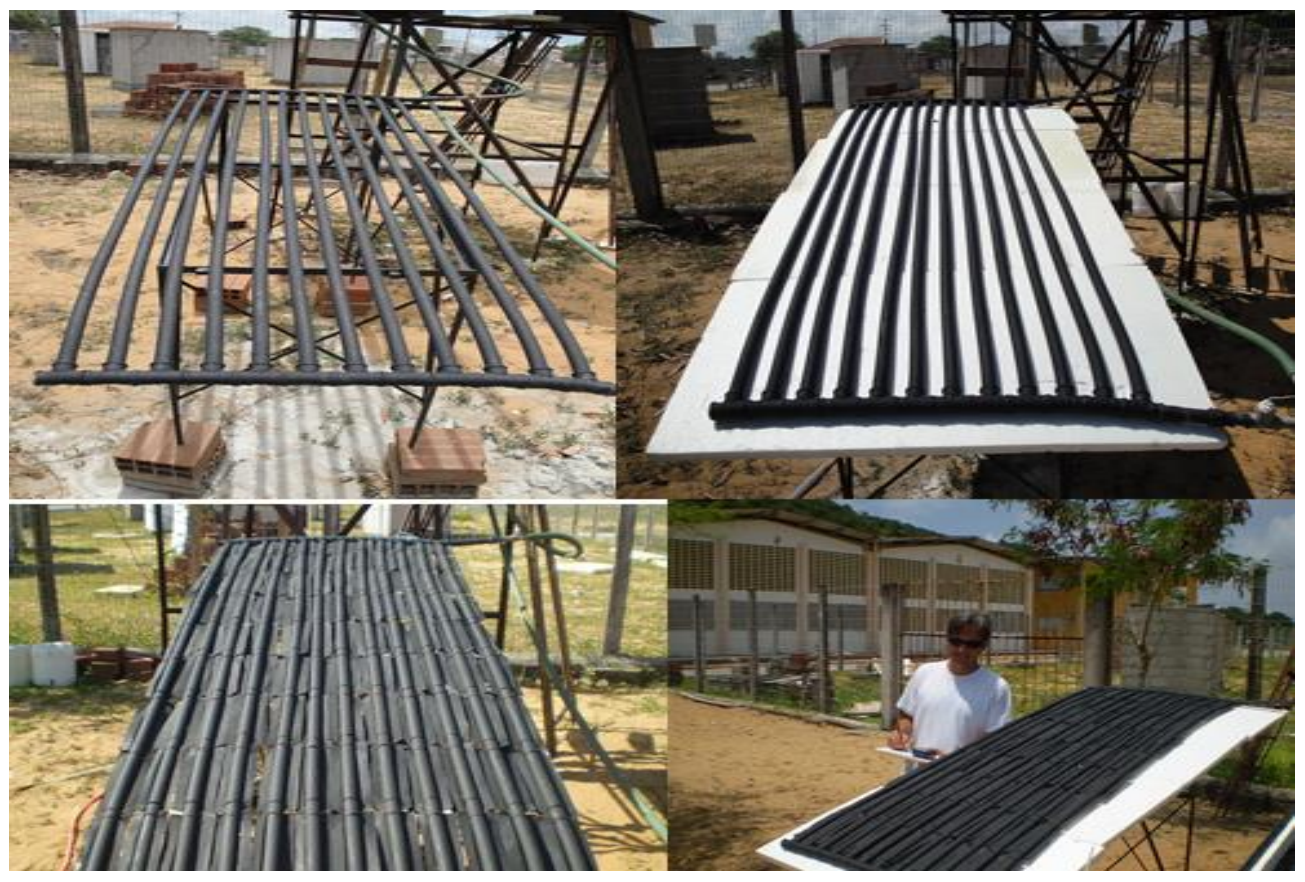

Figura 4 - Quatro diferentes configurações de um sistema de aquecimento solar de água não convencionais sem a apresentação dos reservatórios térmicos

Fonte: Lopo (2010)

Depois de expor os benefícios que a energia solar pode trazer quando é aproveitada como fonte de aquecimento de água através da exposição dos vários tipos de sistemas de aquecimento solar de água desenvolvidos, que foram apresentados no presente item e que obtiveram bons resultados mesmo nas regiões com índices de radiação solar inferiores à média nacional, se torna interessante construir e a analisar um sistema não convencional de aquecimento solar de água em uma região que, segundo Pereira et al. (2006), apresenta os maiores e mais constantes índices de radiação solar do Brasil, ou seja, na região nordeste, mais especificadamente em Mossoró/RN e, em seguida, analisar o comportamento dos equipamentos de baixo custo que serão utilizados em substituição aos equipamentos tradicionalmente utilizados nos sistemas de aquecimento solar de água. 


\section{DETERMINAÇÃO DOS PARÂMETROS TÉRMICOS}

O fator norteador para o planejamento de pesquisa do presente trabalho é o interesse em investigar o comportamento de um aquecedor solar de baixo custo instalado na cidade de Mossoró (RN). Para isso, é necessário determinar os parâmetros fundamentais que auxiliam na determinação do desempenho térmico do SASncbc. De acordo com Lopo (2010), tais parâmetros que se referem ao coletor solar do sistema de aquecimento solar de água são: o coeficiente global de perdas, a potência perdida e o rendimento térmico.

\subsection{COEFICIENTE GLOBAL DE PERDAS}

As perdas térmicas do coletor solar são consequência da parte da energia captada que migra do coletor para a atmosfera por convecção, condução e radiação, devido à diferença de temperatura entre elas. Duffie\&Beckman (1991) apud Lopo (2010), afirma que o Coeficiente Global de Perdas ( $U_{\text {loss }}$ ) é o parâmetro capaz de relacionar todas as perdas de um sistema, seja pelo método da perda térmica, pelo método das trocas térmicas ou pelo método da inversão de fluxo. Como o método da perda térmica, também conhecido como método da potência perdida, apresenta uma boa precisão e uma facilidade de obtenção, o mesmo foi escolhido para analisar o sistema.

Para determinar o Coeficiente Global de Perdas Térmicas é necessário inicialmente conhecer os valores da potência absorvida pelo coletor $\left(P_{a b s}\right)$, a potência transferida ao fluido de trabalho $\left(P_{u}\right)$, e posteriormente a potência perdida pelo coletor $\left(P_{p}\right)$, como mostra as Equações 1 , 2 e 3.

- Potência absorvida pelo coletor $\left(P_{a b s}\right)$ :

Representa quantitativamente a parcela da energia incidente que é absorvida pela placa absorvedora do coletor solar.
$\mathbf{P}_{\mathrm{abs}}=\boldsymbol{\alpha}_{\mathrm{p}} \cdot \mathbf{I} \cdot \mathrm{A}$
Equação (1)

Onde $\mathrm{P}_{\mathrm{abs}}$ é a potência absorvida pelo coletor, em $\mathrm{kW} ; \alpha_{\mathrm{p}}$ representa a absortividade da placa; I refere-se a radiação solar global, em $\mathrm{kW} / \mathrm{m}^{2}$; e A é a área do coletor solar que é exposta a radiação solar, em $\mathrm{m}^{2}$.

- Potência transferida ao fluido de trabalho $\left(P_{u}\right)$ :

Como o próprio nome já diz, essa potência representa a parcela da energia que consegue ser transferida para o fluido de trabalho, no caso, a água.

$\mathbf{P}_{\mathbf{u}}=\dot{\mathbf{m}} \cdot \mathbf{c}_{\mathbf{p}} \cdot \Delta \mathbf{T}$

Equação (2)

Onde $\mathrm{P}_{\mathrm{u}}$ representa a potência útil transferida ao fluido de trabalho, em $\mathrm{kW}$; $\dot{\mathrm{m}}$ é a vazão mássica, em $\mathrm{kg} / \mathrm{s} ; \mathrm{c}_{\mathrm{p}}$ corresponde ao calor específico da água, em $\mathrm{kJ} / \mathrm{kg}{ }^{\circ} \mathrm{C}$; e $\Delta \mathrm{T}$ consiste na diferença de temperatura do fluido obtida no sistema, em ${ }^{\circ} \mathrm{C}$.

- Potência perdida pelo coletor $\left(P_{p}\right)$ :

Parcela da energia absorvida que é perdida através da base, das laterais e do topo do coletor solar.

$\mathbf{P}_{\mathrm{p}}=\mathbf{P}_{\mathrm{abs}}-\mathbf{P}_{\mathbf{u}}$

Equação (3) 
Onde $\mathrm{P}_{\mathrm{p}}$ corresponde a potência perdida pelo coletor, em $\mathrm{kW} ; \mathrm{P}_{\mathrm{abs}}$ refere-se a potência absorvida pelo coletor, em $\mathrm{kW}$; e $\mathrm{P}_{\mathrm{u}}$ consiste na potência útil transferida ao fluido de trabalho, em $\mathrm{kW}$.

Calculada a potência perdida pelo coletor solar e conhecendo a área do coletor exposta à radiação solar $(A)$, a temperatura média da placa $\left(T_{m p}\right)$, assim como a temperatura ambiente $\left(T_{a m b}\right)$, o Coeficiente Global de Perdas Térmicas ( $U_{\text {loss }}$ ) pode ser obtido de acordo com a Equação 4.

$\mathbf{U}_{\text {loss }}=\frac{\mathbf{P}_{\mathbf{p}}}{\mathbf{A} \cdot\left(\mathbf{T}_{\mathbf{m p}}-\mathbf{T}_{\mathbf{a m b}}\right)}$

Equação (4)

Onde $U_{\text {loss }}$ é o coeficiente Global de Perdas Térmicas, em $\mathrm{W} / \mathrm{m}^{2} \mathrm{~K} ; \mathrm{P}_{\mathrm{p}}$ representa a potência perdida pelo coletor, em kW; A corresponde a área do coletor solar que é exposta a radiação solar, em $\mathrm{m}^{2} ; \mathrm{T}_{\mathrm{mp}}$ consiste na temperatura média da placa, ${ }^{\circ} \mathrm{C}$; e $\mathrm{T}_{\mathrm{amb}}$ equivale a temperatura ambiente, em ${ }^{\circ} \mathrm{C}$.

\subsection{RENDIMENTO TÉRMICO}

O rendimento térmico do coletor solar permite a determinação da quantidade de energia que o sistema consegue reter. Esse rendimento pode ser adquirido através da relação entre a potência transferida ao fluido de trabalho $\left(\mathrm{P}_{\mathrm{u}}\right)$, demonstrado na Equação 2; a área do coletor solar exposta à radiação solar (A); e a radiação solar incidente que o coletor solar está exposto, conforme mostra a Equação 5.

$\eta_{t}=\frac{P_{u}}{A \cdot I} \cdot 100$

Equação (5)

$\mathrm{Na}$ qual $\eta_{t}$ é o rendimento térmico do coletor em estudo, em \%; Pu corresponde a potência útil transferida ao fluido de trabalho, em kW; A representa a área do coletor solar que é exposta a radiação solar, em $\mathrm{m}^{2}$; e I consiste na radiação solar global, em kW/m².

Conhecendo todos os parâmetros necessários na determinação da eficiência térmica do sistema, é possível ter conhecimento de todas as medições que influenciam nos cálculos que necessitam ser realizados nas análises.

\section{MATERIAIS E MÉTODOS}

Será analisado um sistema de aquecimento solar utilizando materiais não convencionais, ou seja, materiais alternativos de baixo custo, composto por um coletor solar plano e um reservatório térmico para o armazenamento de água quente.

O coletor solar plano possui área de $2,00 \mathrm{~m}^{2}$ e é constituído por três dos cinco elementos normalmente utilizados na confecção de um coletor solar convencional, que são: chapa absorvedora ou aletas, grade absorvedora, e caixa armazenadora, não possuindo cobertura de material transparente e isolamento térmico.

Quanto ao reservatório térmico, também conhecido na literatura como boiler, esse tem uma capacidade de 120 litros, podendo simplificar sua denominação por RT 120 . O modelo construído é constituído pelos três principais elementos usuais de um reservatório térmico convencional, que são: corpo interno cilíndrico, isolante térmico e cobertura. Diferente dos 
reservatórios térmicos convencionais comercializados no mercado, o reservatório do sistema construído no presente trabalho não apresenta sistema de aquecimento auxiliar.

O sistema de aquecimento solar foi acomodado na área externa do Laboratório de Engenharia de Energia e Mecânica da UFERSA, localizado no Campus Leste da UFERSA Mossoró(RN). Sua instalação foi realizada de tal modo que garantiu a inclinação de 15,1 으, ou seja, 10 a mais do que a latitude da cidade de Mossoró, como é indicado por Alves (2009) para que haja maior aproveitamento da radiação solar global ao longo do ano. O sistema também foi posicionado de maneira que obedeça a condição do coletor ter sua face voltada para o norte geográfico. Por fim, após a instalação do SASncbc, foi verificado que o sistema não possuía vazamentos e que a circulação em regime de convecção natural estava sendo atendida.

Dando continuidade ao trabalho, os itens 4.1, 4.2 e 4.3 apresentarão as informações relacionadas ao local da pesquisa; os instrumentos utilizados na coleta de dados; e por fim, serão mostrados os procedimentos de coleta de dados que serão realizados.

\subsection{CARACTERIZAÇÃO DA CIDADE DE MOSSORÓ (RN)}

A pesquisa de campo será realizada na cidade de Mossoró, localizada no Estado do Rio Grande do Norte, ou seja, na região Nordeste do Brasil, como mostra a Figura 5. A cidade de Mossoró encontra-se próxima à linha do equador, e desta forma, quase não se observa alterações nos dias de sol ao longo de um ano. Em linhas gerais, a cidade está localizada na mesorregião oeste (3720' de longitude Oeste e 511' de latitude Sul) do Estado, com uma altitude média de $18 \mathrm{~m}$ acima do nível do mar e situada a $280 \mathrm{~km}$ da capital potiguar (LEITÃO et al., 2000).

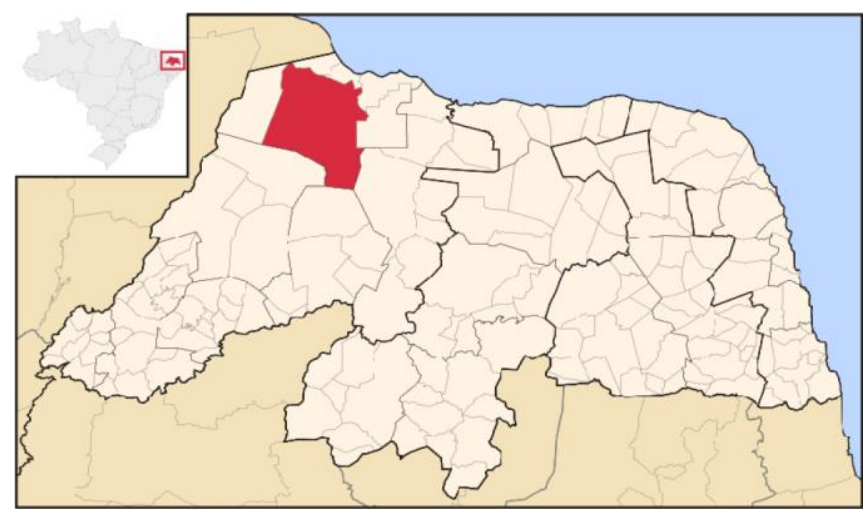

Figura 5 - Localização da cidade de Mossoró/RN. Fonte: Simonsen, 2010

Mossoró possui um clima semiárido seco, muito quente e com estação chuvosa no verão e no outono. Sua temperatura média anual é de $27,6 \circ \mathrm{C}$, podendo variar entre $22,8 \circ \mathrm{C}$ e $33,5 \circ \mathrm{C}$, sendo julho o mês mais frio e dezembro o mês mais quente. A umidade relativa média anual da cidade é de 68,1\%; a nebulosidade média anual de 40\%; e a insolação média anual é de 241,7 horas (LEITÃO et al., 2000). Ainda possui uma radiação solar média anual de $18,0 \mathrm{MJ} / \mathrm{m}^{2}$.dia (FAE-UFPE; CEPEL, 2000).

Vale ressaltar que a escolha do local da pesquisa levou em consideração o fato da Instituição, no caso, UFERSA, possuir os equipamentos necessários para coletar os dados e realizar 
as observações in loco, como também por estar localizada próxima à Estação Meteorológica de Mossoró-RN.

\subsection{CARACTERIZAÇÃO DOS EQUIPAMENTOS DE MEDIÇÃO}

Após a instalação do SASncbc no local selecionado, é necessário ensaiar o sistema com a finalidade de determinar a sua eficiência térmica através dos parâmetros pré-estabelecidos por Lopo (2010). Para isso, é fundamental a utilização de dois equipamentos para que as medições da coleta de dados sejam feitas. Um termômetro (fabricante ICEL, modelo MD-5770), que no caso será utilizado um multímetro digital na função de termômetro juntamente com um termopar do tipo K, nas medições de temperatura. Também foi utilizado o medidor de energia solar digital e portátil que serve para coletar os dados de radiação solar, que também é do fabricante INSTRUTHERM, modelo MES-100.

Além dos equipamentos supracitados, foi necessário utilizar outro termômetro digital, o Hygro/Thermo Sensor TS34C de 5 canais para que os dados de temperatura ambiente e umidade relativa do ar fossem obtidos com maior precisão.

Com o auxílio dos equipamentos citados anteriormente, é possível ser realizado o procedimento de coleta de dados explicitados no item 4.3 para que sejam realizados ensaios e análises posteriores.

\subsection{PROCEDIMENTO DE COLETA DE DADOS}

O sistema é ensaiado com a finalidade de determinar a sua eficiência térmica através dos parâmetros pré-estabelecidos por Lopo (2010). Foram analisados o desempenho térmico, bem como a susceptibilidade ${ }^{2}$ dos tubos de PVC, já que, de acordo com Lopo (2010), o PVC atinge o nível crítico para o início da degradação térmica quando a temperatura está em torno de 60 ㄷ.
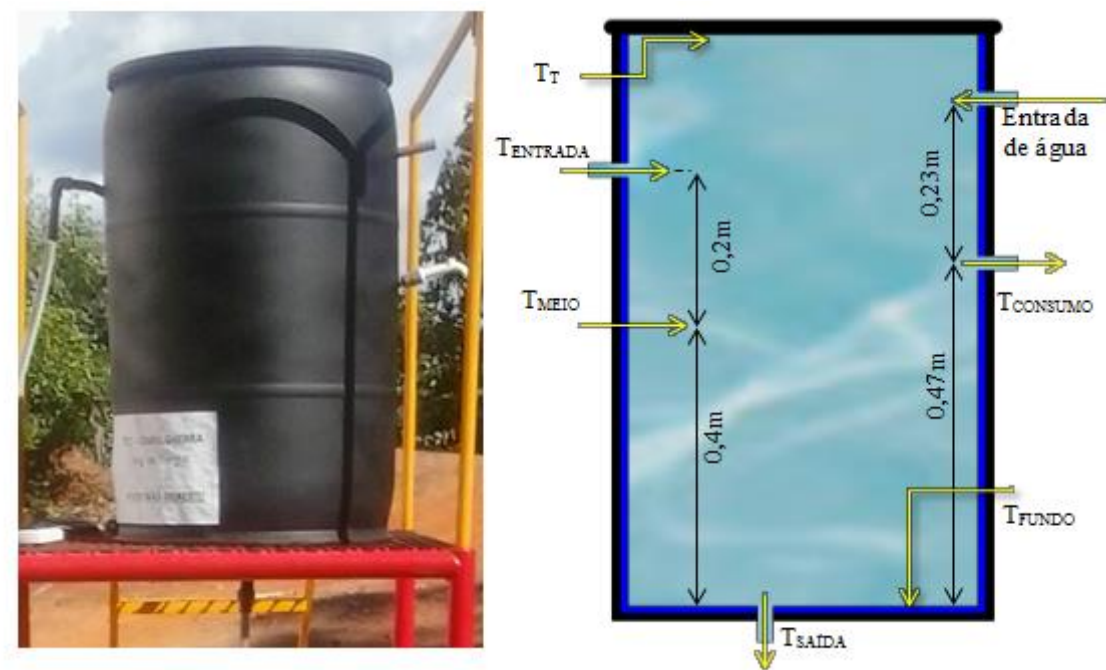

Figura 6 - Detalhe dos pontos de medida de temperatura da água contida no reservatório.

Fonte: GUERRA, 2012

\footnotetext{
2 Tendência a sofrer influências ou deformações.
} 
As análises foram realizadas no decorrer de 4 dias. As condições solarimétricas, os índices de radiação solar global e a nebulosidade foram variados, contribuindo para uma análise tanto em dia nebuloso quanto em um dia de sol pleno.

Inicialmente foi medida a temperatura da água entregue pela distribuidora, com o auxílio de um termômetro digital e seu respectivo termopar tipo K. Em seguida, foram medidas, a cada 1 hora entre o horário das 8:00h às 15:00h, as temperaturas em diferentes pontos do reservatório, como mostra a Figura 6 e que possuem a seguinte ordem de medição: temperatura no topo do reservatório $\left(\mathrm{T}_{\mathrm{T}}\right)$; temperatura na entrada da água oriunda do coletor ( $\mathrm{T}_{\mathrm{ENTRADA}}$ ); temperatura de saída para consumo ( $\mathrm{T}_{\text {CONSUMO }}$ ); temperatura no meio do reservatório ( $\mathrm{T}_{\mathrm{MEIO}}$ ); temperatura no fundo do reservatório ( $T_{F U N D O}$ ); e temperatura na saída da água para o reservatório (TSAíDA).

É válido ressaltar que será considerada como temperatura final da água, aquela medida após as sete horas de funcionamento do SASncbc. Em seguida, como mostra a Figura 7, foi verificada a temperatura na entrada $\left(\mathrm{T}_{\mathrm{EC}}\right)$ e saída $\left(\mathrm{T}_{\mathrm{SC}}\right)$ do fluido do coletor solar.

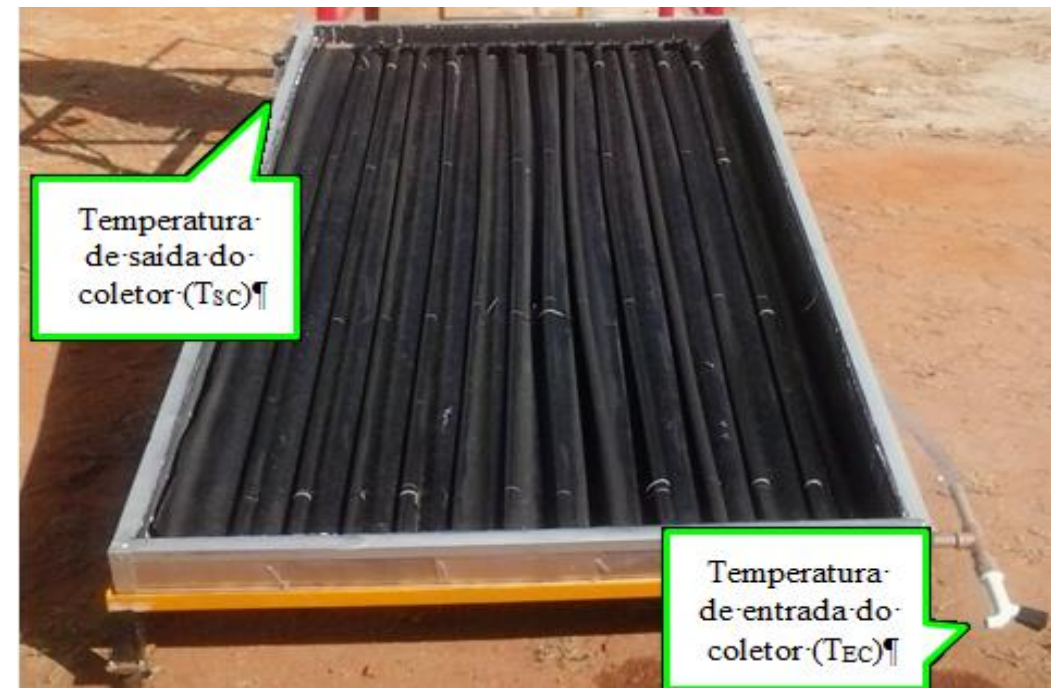

Figura 76 - Detalhes do local de medição da entrada e saída de água do coletor solar. Fonte: GUERRA, 2012

Posteriormente, com o auxílio do medidor de energia solar digital foi verificada a radiação solar global, apenas apontando o equipamento portátil para o norte, ou seja, para a mesma direção que o coletor solar encontra-se posicionado.

Já para a análise da susceptibilidade dos tubos de PVC, foram medidas as temperaturas em diferentes pontos da grade e dos tubos absorvedores do coletor, como é destacado e assinalado com um " $X$ " na Figura 8, no período de radiação máxima e mais constantes, ou seja, entre 11:00h e 13:00h. Lembrando sempre que é desejável que essa temperatura medida não alcance $60^{\circ} \mathrm{C}$, por motivos já expostos.

Com os dados obtidos das temperaturas da grade absorvedora também é possível avaliar a perda máxima do coletor solar. Por fim, para testar a eficiência térmica do reservatório térmico não convencional, foi verificada a temperatura da água contida no reservatório no final do quarto dia de funcionamento do sistema, ou seja, ás 15:00h. Em seguida, foram retiradas as mangueiras de ligação que existiam no reservatório com outros meios para que a troca térmica fosse evitada ao máximo durante a noite. Pela manhã do quinto dia de análise, a temperatura da água do 
reservatório foi medida da mesma forma que é indicada na Figura 9, para que a perda térmica fosse analisada.

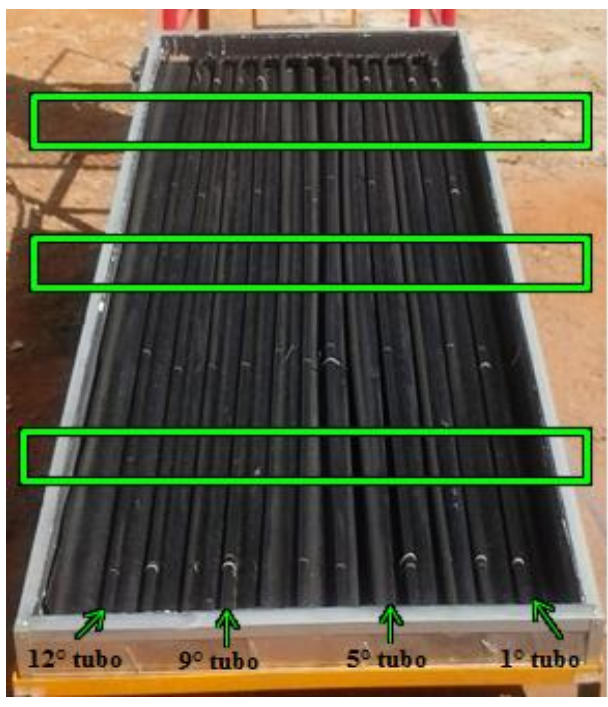

\begin{tabular}{|c|c|c|c|c|c|}
\cline { 2 - 5 } \multicolumn{1}{c|}{} & $\begin{array}{c}12^{\circ} \\
\text { tubo }\end{array}$ & $\begin{array}{c}9^{\circ} \\
\text { tubo }\end{array}$ & $\begin{array}{c}5^{\circ} \\
\text { tubo }\end{array}$ & $\begin{array}{c}1^{\circ} \\
\text { tubo }\end{array}$ & Médias \\
\hline Tubo & $\mathrm{X}$ & $\mathrm{X}$ & $\mathrm{X}$ & $\mathrm{X}$ & \\
\hline Aleta & $\mathrm{X}$ & $\mathrm{X}$ & $\mathrm{X}$ & $\mathrm{X}$ & \\
\hline & & & & & \\
\hline Tubo & $\mathrm{X}$ & $\mathrm{X}$ & $\mathrm{X}$ & $\mathrm{X}$ & \\
\hline Aleta & $\mathrm{X}$ & $\mathrm{X}$ & $\mathrm{X}$ & $\mathrm{X}$ & \\
\hline & & & & & \\
\hline Tubo & $\mathrm{X}$ & $\mathrm{X}$ & $\mathrm{X}$ & $\mathrm{X}$ & \\
\hline Aleta & $\mathrm{X}$ & $\mathrm{X}$ & $\mathrm{X}$ & $\mathrm{X}$ & \\
\hline & & & & & \multicolumn{2}{|c|}{} \\
\cline { 2 - 5 } & & & &
\end{tabular}

Figura 87 - Destaque dos pontos de medição de temperatura da grade absorvedora do sistema. Fonte: GUERRA, 2012

Finalizadas todas as medições no decorrer dos quatro dias de análise foi possível calcular os parâmetros térmicos fundamentais que determinam o coeficiente global de perdas e o rendimento térmico do SASncbc. Consequentemente, todas os resultados obtidos com o ensaio do SASncbc poderão ser analisados e avaliados, e assim, verificado o desempenho térmico desse sistema.

\section{ANÁLISE DOS RESULTADOS}

Serão avaliados os resultados obtidos nos quatro dias de análise do sistema de aquecimento solar proposto, sendo três dias utilizados para o estudo do coletor solar e um dia necessário para o estudo do reservatório térmico, ambos não convencionais e de baixo custo.

Esses resultados analisam a susceptibilidade à degradação térmica do PVC que compõe o coletor solar térmico; bem como são utilizados para validar os parâmetros utilizados nos cálculos que determinam a eficiência térmica do coletor solar; e o coeficiente global de perdas do sistema de aquecimento solar. Além disso, os resultados também são necessários para verificar o comportamento da temperatura da água no interior do reservatório térmico e averiguar as possíveis perdas térmicas no reservatório térmico.

\subsection{ANÁLISE DA SUSCEPTIBILIDADE À DEGRADAÇÃO TÉRMICA DO PVC COMPOSTO NO COLETOR SOLAR NÃO CONVENCIONAL E DE BAIXO CUSTO EM ESTUDO}

Para realização desta análise, foi verificada a temperatura que a água atingiu na saída do coletor solar, assim como os valores de temperatura medidos nas aletas e tubos absorvedores do sistema de aquecimento solar em estudo.

Os gráficos das Figuras 9, 10 e 11 mostram, respectivamente, as temperaturas de entrada ( $T_{E C}$ ) e saída ( $\left.T_{S C}\right)$ do coletor solar não convencional; a diferença entre essas temperaturas $(\Delta T)$; e 
destaca o nível de $60^{\circ} \mathrm{C}$, como a máxima temperatura que a água pode atingir para que o sistema não seja comprometido devido ao início da degradação térmica que o PVC pode atingir, para cada um dos três dias de análise.

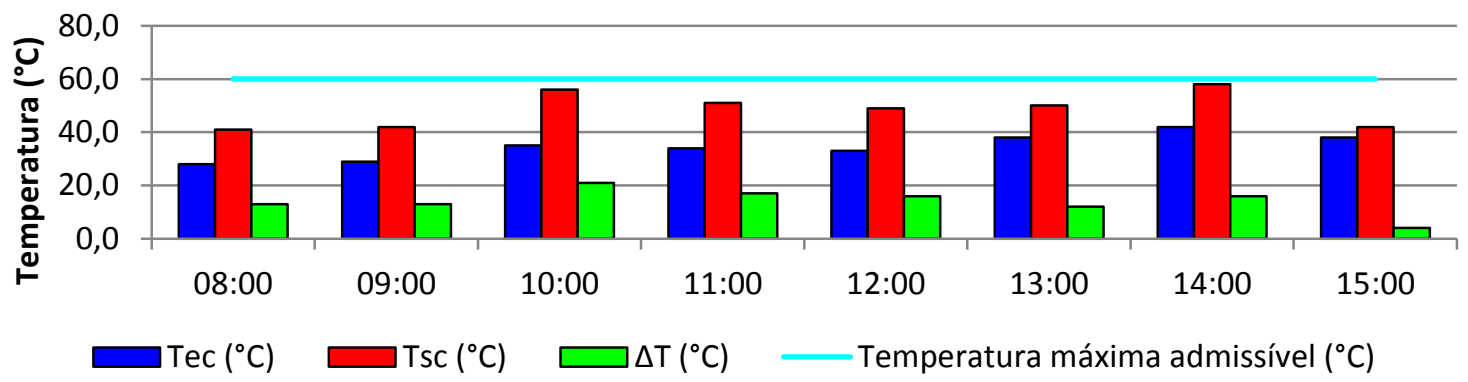

Figura 9 - Comportamento das temperaturas médias horárias de entrada e saída do coletor no primeiro dia de ensaio (01/06/2012).

Fonte: GUERRA, 2012

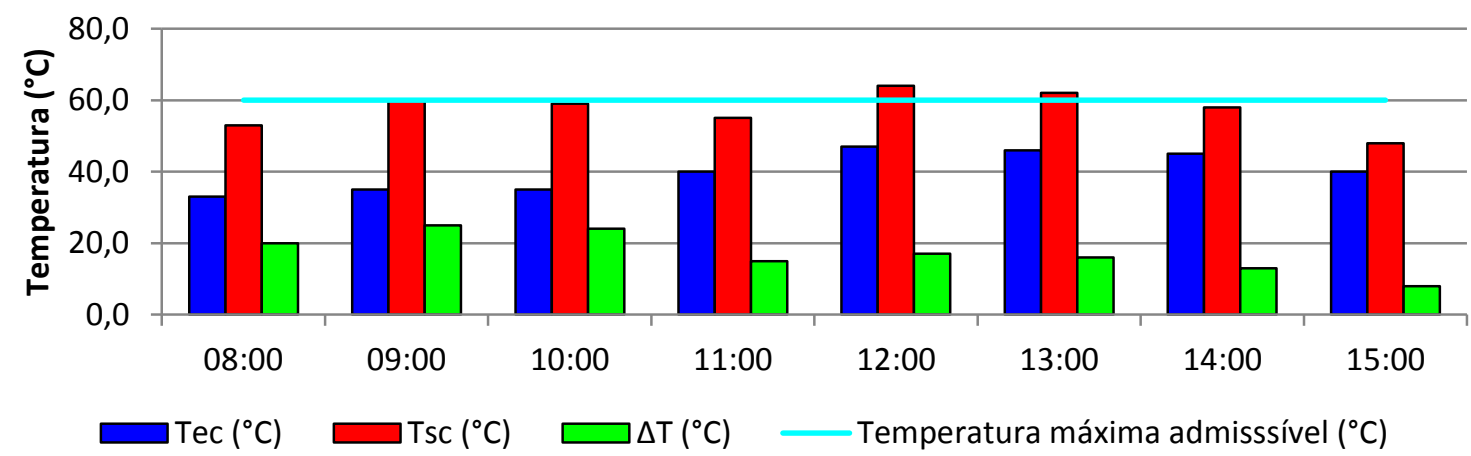

Figura 108 - Comportamento das temperaturas médias horárias de entrada e saída do coletor no segundo dia de ensaio (04/06/2012).

Fonte: GUERRA, 2012

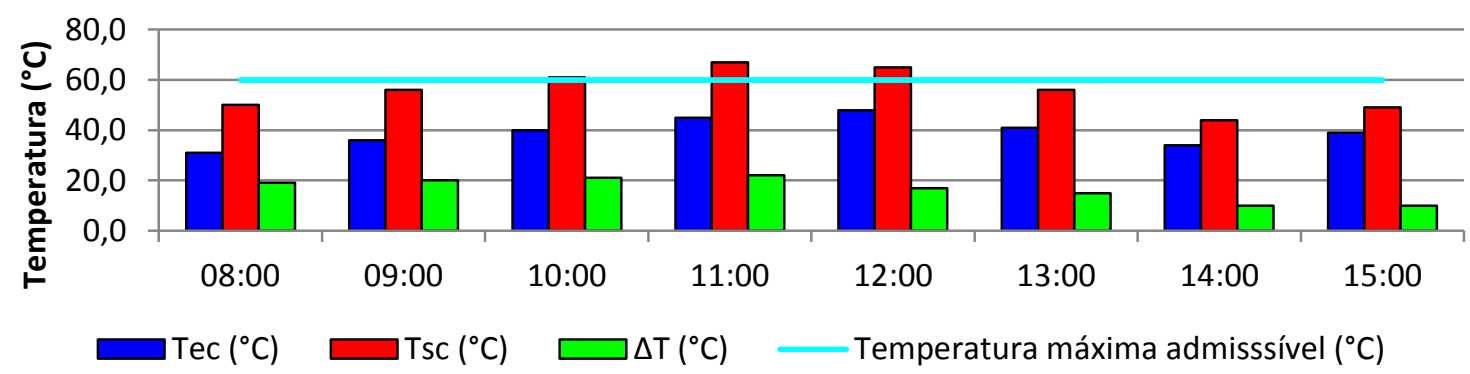

Figura 11 - Comportamento das temperaturas médias horárias de entrada e saída do coletor no terceiro dia de ensaio (05/06/2012).

Fonte: GUERRA, 2012

O gráfico da Figura 9 mostra que durante todo o primeiro dia de análise a água percorrida pelo interior do coletor solar não convencional e de baixo custo é inferior aos $60^{\circ} \mathrm{C}$ máximo admissível, apesar da temperatura da água de saída ter atingido $58^{\circ} \mathrm{C}$ às $14: 00 \mathrm{~h}$, ou seja, próximo ao valor permitido. Entretanto, analisando os gráficos das Figuras 10 e 11, observa-se que a temperatura de $60^{\circ} \mathrm{C}$ foi atingida já nas primeiras horas de funcionamento do coletor solar.

No segundo dia de ensaio, como mostra a Figura 10, a água atinge na saída do coletor a temperatura de $60^{\circ} \mathrm{C}$ às $9: 00 \mathrm{~h}$; às $12: 00 \mathrm{~h}$ alcança os $64^{\circ} \mathrm{C}$; e às $13: 00 \mathrm{~h}$ chega aos $62^{\circ} \mathrm{C}$. Quanto ao 
terceiro dia de teste, mostrado na Figura 11, o coletor solar em análise atinge na saída a temperatura de $61^{\circ} \mathrm{C}$ às $10: 00 \mathrm{~h}$; às $11: 00 \mathrm{~h}$ alcança sua máxima temperatura, chegando a $67^{\circ} \mathrm{C}$ e; por fim, às $12: 00 \mathrm{~h}$, chega aos $65^{\circ} \mathrm{C}$.

Para complementar a avaliação da susceptibilidade do PVC do coletor solar não convencional e de baixo custo à degradação térmica e por radiação, foram verificadas as temperaturas das superfícies externas superior e inferior do PVC dos tubos da placa absorvedora para cada dia de análise já mencionados e nas três horas (11h, 12h e 13h) que apresentam maiores índices de radiação solar, como mostra, respectivamente, as Figuras 12, 13 e 14.

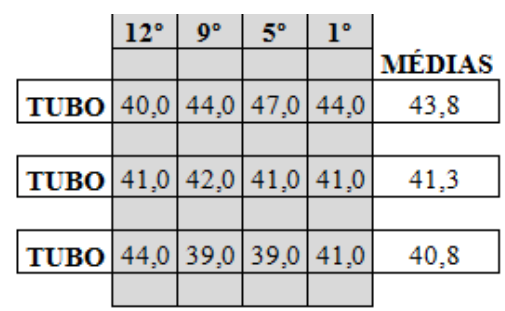

(a)

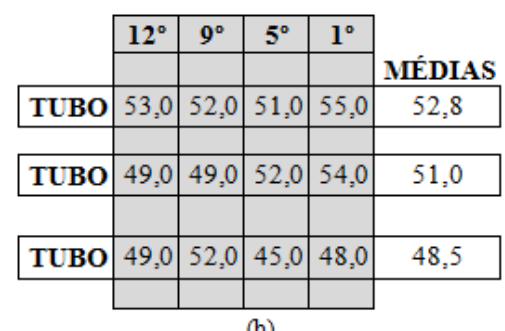

(b)

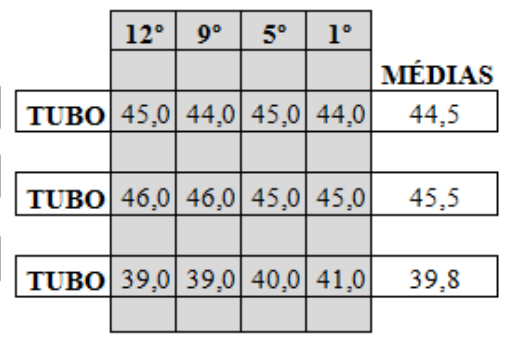

(c)

Figura 12 - Temperaturas médias, em graus Celsius, em diversos pontos no tubo de PVC da placa absorvedora, às (a) 11:00h, (b) 12:00h e (c) 13:00h, no primeiro dia de ensaio (01/06/2012).

Fonte: GUERRA, 2012

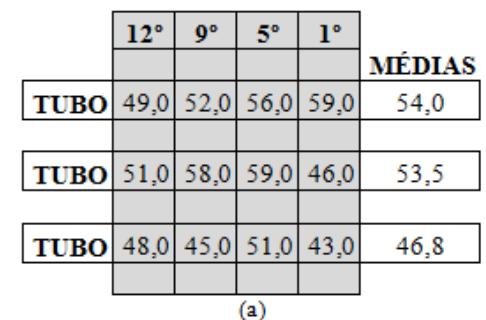

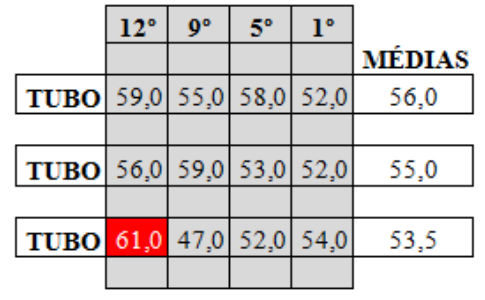

(b)

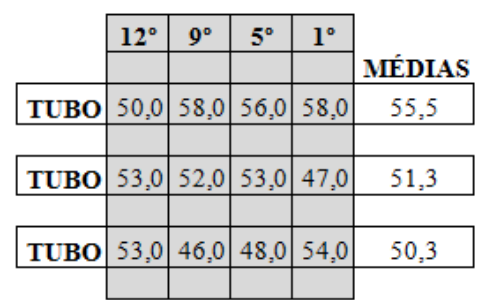

(c)

Figura 13 - Temperaturas médias, em graus Celsius, em diversos pontos no tubo de PVC da placa absorvedora, às (a) 11:00h, (b) 12:00h e (c) 13:00h, no segundo dia de ensaio (04/06/2012). Fonte: GUERRA, 2012 


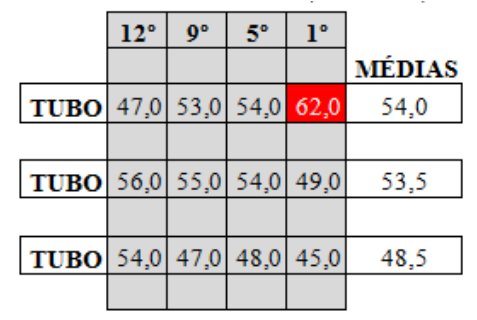

(a)

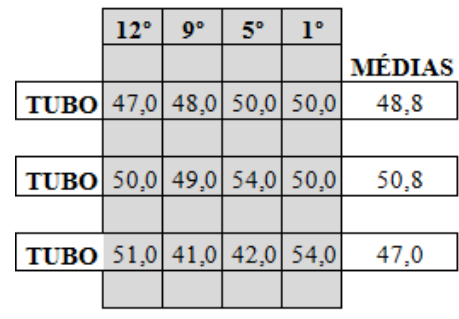

(b)

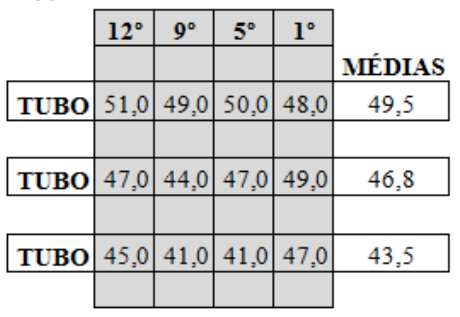

(c)

Figura 149 - Temperaturas médias, em graus Celsius, em diversos pontos no tubo de PVC da placa absorvedora, às (a) 11:00h, (b) 12:00h e (c) 13:00h, no terceiro dia de ensaio (05/06/2012).

Fonte: GUERRA, 2012

Os valores medidos que foram apresentados na Figura 12 mostram que os níveis de temperatura não atingiram a máxima temperatura admissível, ou seja, $60^{\circ} \mathrm{C}$, embora tenha atingindo em alguns pontos valores próximos a esses, como foi o caso do máximo valor medido nesse primeiro dia de ensaio de $55^{\circ} \mathrm{C}$.

Por outro lado, o segundo e terceiro dias de ensaio, como mostram as Figuras 13 e 14, obtiveram níveis de temperatura no tubo de PVC do coletor solar analisado que ultrapassaram o valor de $60^{\circ} \mathrm{C}$. Além disso, em ambos os dias o coletor em estudo manteve uma temperatura média próxima aos $50^{\circ} \mathrm{C}$, ou seja, próximo ao limite permitido.

Desta forma, analisando os gráficos das Figuras 9, 10 e 11, assim como analisando os valores medidos e expostos nas Figuras 12, 13 e 14, é possível verificar que os níveis de temperatura da água que estão em contato direto com os tubos de PVC, bem como os níveis de temperatura dos próprios tubos de PVC que estão expostos à radiação solar e que compõem o coletor solar não convencional e de baixo custo, não só atingiram, como também ultrapassaram o nível crítico para início da degradação térmica do $\mathrm{PVC}$, que é de $60^{\circ} \mathrm{C}$, conforme supracitado.

Após a análise da susceptibilidade à degradação térmica dos tubos de PVC que compõem o coletor solar não convencional e de baixo custo, são mostrados os resultados da eficiência térmica do coletor solar em estudo, a partir dos resultados obtidos através dos parâmetros térmicos do mesmo.

\subsection{RESULTADOS DOS PARAMETROS TÉRMICOS PARA DETERMINAÇÃO DA EFICIÊNCIA DO COLETOR SOLAR NÃO CONVENCIONAL E DE BAIXO CUSTO EM ESTUDO}

As Tabelas 1, 2 e 3 mostram os valores medidos da temperatura de entrada ( $T_{E C}$ ) e saída ( $\left.T_{s c}\right)$ do coletor solar em análise; a diferença entre essas temperaturas $(\Delta T)$; a radiação solar (ICOLETOR); a potência útil transferida ao fluido de trabalho ( $\mathrm{Pu})$; assim como o resultado do cálculo de rendimento térmico do coletor solar $\left(\eta_{t}\right)$, tanto para cada hora de funcionamento no decorrer de cada dia de análise, ou seja, entre às 8:00h e 15:00h, como uma média geral de cada dia. 
Tabela 1 - Dados do primeiro dia de ensaio (01/06/2012).

\begin{tabular}{|c|c|c|c|c|c|c|}
\hline \multirow{2}{*}{$\begin{array}{c}\text { TEMPO } \\
\text { (h) }\end{array}$} & \multicolumn{2}{|c|}{ Coletor } & \multirow{2}{*}{$\Delta \mathrm{T}\left({ }^{\circ} \mathrm{C}\right)$} & \multirow{2}{*}{ Icoletor $\left(\mathrm{kW} / \mathrm{m}^{2}\right)$} & \multirow{2}{*}{$\mathrm{Pu}(\mathrm{kW})$} & \multirow{2}{*}{ nt (\%) } \\
\hline & $\operatorname{Tec}\left({ }^{\circ} \mathrm{C}\right)$ & $\operatorname{Tsc}\left({ }^{\circ} \mathrm{C}\right)$ & & & & \\
\hline 08:00 & 28,0 & 41,0 & 13,0 & 0,4187 & 0,2588 & 30,90 \\
\hline 09:00 & 29,0 & 42,0 & 13,0 & 1,1420 & 0,2588 & 11,33 \\
\hline 10:00 & 35,0 & 56,0 & 21,0 & 1,2480 & 0,4180 & 16,75 \\
\hline 11:00 & 34,0 & 51,0 & 17,0 & 1,4660 & 0,3384 & 11,54 \\
\hline $12: 00$ & 33,0 & 49,0 & 16,0 & 1,3520 & 0,3185 & 11,78 \\
\hline $13: 00$ & 38,0 & 50,0 & 12,0 & 0,7885 & 0,2389 & 15,15 \\
\hline $14: 00$ & 42,0 & 58,0 & 16,0 & 1,1150 & 0,3185 & 14,28 \\
\hline $15: 00$ & 38,0 & 42,0 & 4,0 & 0,6646 & 0,0796 & 5,99 \\
\hline Média & 34,6 & 48,6 & 14,0 & 1,0244 & 0,2787 & 14,71 \\
\hline
\end{tabular}

Tabela 2 - Dados do segundo dia de ensaio (04/06)

\begin{tabular}{|c|c|c|c|c|c|c|}
\hline \multirow{2}{*}{$\begin{array}{c}\text { TEMPO } \\
\text { (h) }\end{array}$} & \multicolumn{2}{|c|}{ Coletor } & \multirow{2}{*}{$\Delta \mathrm{T}\left({ }^{\circ} \mathrm{C}\right)$} & \multirow{2}{*}{ Icoletor $\left(\mathrm{W} / \mathrm{m}^{2}\right)$} & \multirow{2}{*}{$\mathrm{Pu}(\mathrm{kW})$} & \multirow{2}{*}{ nt (\%) } \\
\hline & $\operatorname{Tec}\left({ }^{\circ} \mathrm{C}\right)$ & $\operatorname{Tsc}\left({ }^{\circ} \mathrm{C}\right)$ & & & & \\
\hline 08:00 & 33,0 & 53,0 & 20,0 & 1,121 & 0,3981 & 17,76 \\
\hline 09:00 & 35,0 & 60,0 & 25,0 & 1,258 & 0,4976 & 19,78 \\
\hline $10: 00$ & 35,0 & 59,0 & 24,0 & 1,336 & 0,4777 & 17,88 \\
\hline $11: 00$ & 40,0 & 55,0 & 15,0 & 1,400 & 0,2986 & 10,66 \\
\hline $12: 00$ & 47,0 & 64,0 & 17,0 & 1,301 & 0,3384 & 13,00 \\
\hline $13: 00$ & 46,0 & 62,0 & 16,0 & 1,182 & 0,3185 & 13,47 \\
\hline $14: 00$ & 45,0 & 58,0 & 13,0 & 0,840 & 0,2588 & 15,40 \\
\hline $15: 00$ & 40,0 & 48,0 & 8,0 & 0,540 & 0,1592 & 14,74 \\
\hline Média & 40,125 & 57,375 & 17,3 & 1,122 & 0,3434 & 15,34 \\
\hline
\end{tabular}

Fonte: GUERRA, 2012.

Tabela 3 - Dados do terceiro dia de ensaio (05/06/2012)

\begin{tabular}{|c|c|c|c|c|c|c|}
\hline \multirow{2}{*}{$\begin{array}{c}\text { TEMPO } \\
\text { (h) }\end{array}$} & \multicolumn{2}{|c|}{ Coletor } & \multirow{2}{*}{$\Delta \mathrm{T}\left({ }^{\circ} \mathrm{C}\right)$} & \multirow{2}{*}{ Icoletor $\left(\mathrm{W} / \mathrm{m}^{2}\right)$} & \multirow{2}{*}{$\mathrm{Pu}(\mathrm{kW})$} & \multirow{2}{*}{ nt (\%) } \\
\hline & $\operatorname{Tec}\left({ }^{\circ} \mathrm{C}\right)$ & $\operatorname{Tsc}\left({ }^{\circ} \mathrm{C}\right)$ & & & & \\
\hline 08:00 & 31,0 & 50,0 & 19,0 & 0,942 & 0,3782 & 20,07 \\
\hline 09:00 & 36,0 & 56,0 & 20,0 & 1,223 & 0,3981 & 16,28 \\
\hline $10: 00$ & 40,0 & 61,0 & 21,0 & 1,207 & 0,4180 & 17,32 \\
\hline $11: 00$ & 45,0 & 67,0 & 22,0 & 1,281 & 0,4379 & 17,09 \\
\hline $12: 00$ & 48,0 & 65,0 & 17,0 & 1,168 & 0,3384 & 14,49 \\
\hline 13:00 & 41,0 & 56,0 & 15,0 & 1,290 & 0,2986 & 11,57 \\
\hline $14: 00$ & 34,0 & 44,0 & 10,0 & 1,009 & 0,1990 & 9,86 \\
\hline $15: 00$ & 39,0 & 49,0 & 10,0 & 0,764 & 0,1990 & 13,03 \\
\hline Média & 39,25 & 56 & 16,8 & 1,110 & 0,3334 & 14,96 \\
\hline
\end{tabular}

Fonte: GUERRA, 2012.

Para o cálculo da potência útil transferida ao fluido de trabalho $\left(\mathrm{P}_{\mathrm{U}}\right)$ e do rendimento térmico do coletor $\left(\eta_{\mathrm{t}}\right)$ das Tabelas 1,2 e 3 foram consideradas a vazão mássica $(\dot{\mathrm{m}})$ igual a $0,004762 \mathrm{~kg} / \mathrm{s}$, uma vez que o reservatório térmico suporta 120 litros de água e o tempo de 
funcionamento diário do sistema é de 7 horas, ou seja, 25.200 segundos; a área do coletor solar alternativo equivalente a $2 \mathrm{~m}^{2}$; e a constante do calor específico da água de $4,18 \mathrm{~kJ} / \mathrm{kg}$, ${ }^{\circ} \mathrm{C}$, que corresponde a $1 \mathrm{kcal} / \mathrm{kg} .{ }^{\circ} \mathrm{C}$.

Os gráficos apresentados nas Figuras 15, 16 e 17 mostram as oscilações dos rendimentos calculados do coletor solar, respectivamente, nas Tabelas 1, 2 e 3 ao longo de cada dia, bem como destaca o rendimento médio medido em cada um desses dias de análise.

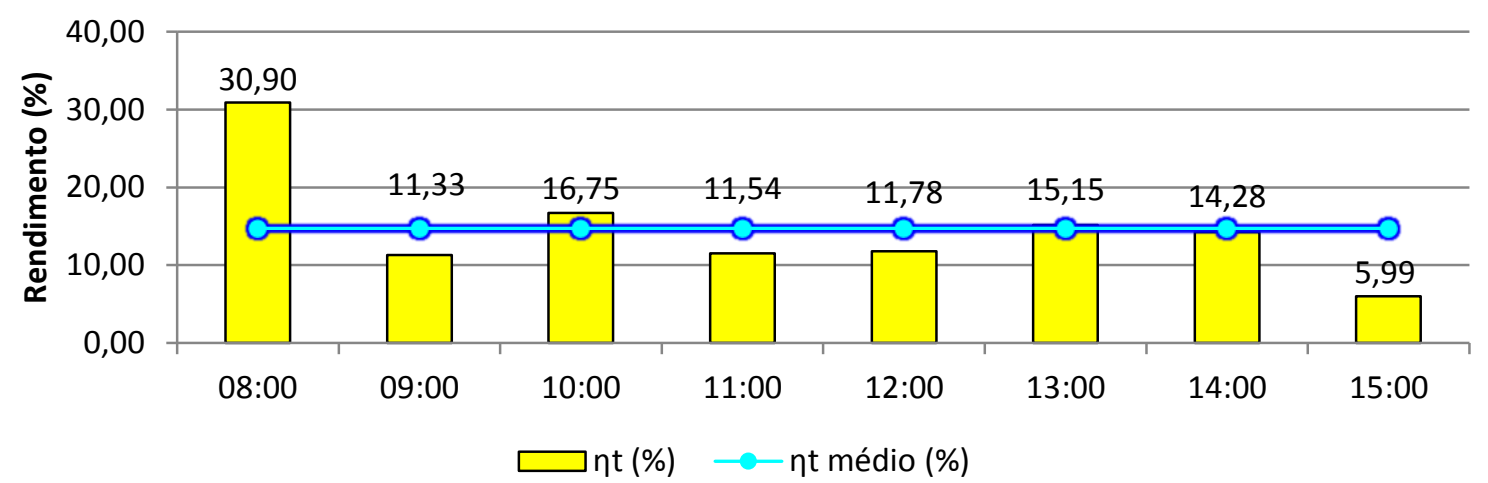

Figura 15 - Rendimento do coletor solar não convencional no primeiro dia de análise (01/06/2012). Fonte: GUERRA, 2012

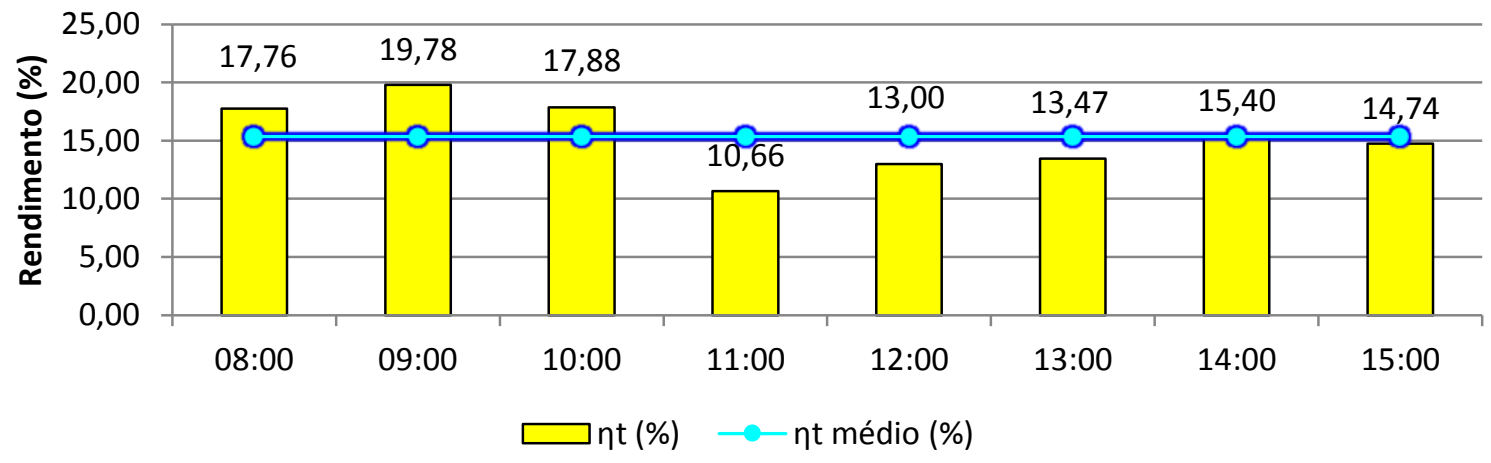

Figura 16 - Rendimento do coletor solar não convencional no segundo dia de análise (04/06/2012). Fonte: GUERRA, 2012

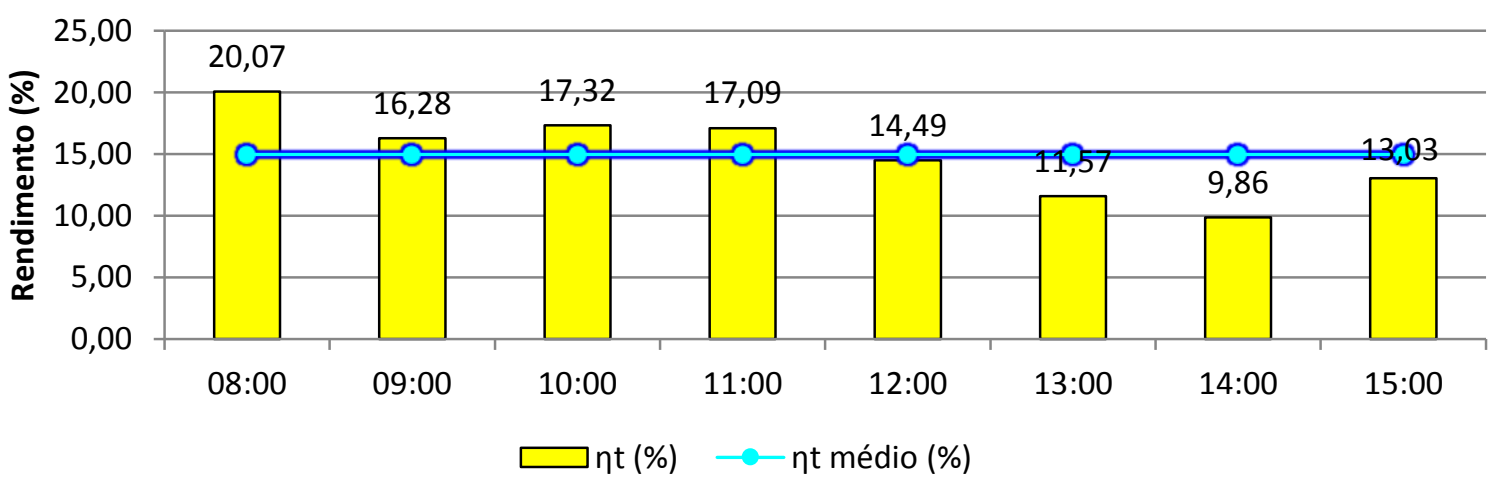

Figura 17 - Rendimento do coletor solar não convencional no terceiro dia de análise (05/06/2012). Fonte: GUERRA, 2012 
Analisando os dados das Tabelas 1, 2 e 3, assim como os gráficos das Figuras 15, 16 e 17, constata-se que o maior rendimento calculado ao longo dos três dias de estudo, ocorreu às 8:00 horas do primeiro dia de análise (01/06), quando o coletor conseguiu atingir um rendimento de 30,90\%, apesar desse dia e horário não apresentar os maiores índices de temperatura. Isso se deve ao fato da obtenção de uma considerável diferença de temperatura $(\Delta T)$, mesmo com a radiação solar abaixo da média do dia.

Além disso, é verificado que o primeiro dia de estudo teve um rendimento médio de 14,71\%; o segundo dia atingiu 15,34\%; e o terceiro e último dia, o rendimento médio calculado foi de $14,96 \%$. É possível perceber a presença de um baixo rendimento do coletor solar não convencional quando comparado com outros coletores solares não convencionais já estudados, como o de Lopo (2010), por exemplo, apesar de ter sido registradas temperaturas de saída acima de $40^{\circ} \mathrm{C}$ nas Tabelas 1,2 e 3 . Nem mesmo quando foi atingida a maior média horária, ou seja, 67으, os números mostraram bons rendimentos.

A Tabela 4 mostra os resultados médios gerais encontrados para os três dias de análise e confirma o baixo rendimento do coletor solar não convencional e de baixo custo ao final dos três dias de análise.

Tabela 4 - Resultado médio geral do coletor solar não convencional estudado

\begin{tabular}{ccccc}
\hline Dias de Ensaio & $\mathbf{\Delta T}\left({ }^{\circ} \mathrm{C}\right)$ & Icoletor $\left(\mathbf{W} / \mathbf{m}^{2}\right)$ & $\mathbf{P u}(\mathbf{k W})$ & nt (\%) \\
\hline DIA 1 & 14,0 & 1,0244 & 0,2787 & 14,71 \\
DIA 2 & 17,3 & 1,1223 & 0,3434 & 15,34 \\
DIA 3 & 16,8 & 1,1100 & 0,3334 & 14,96 \\
\hline Média & 16,0 & 1,0855 & 0,3185 & 15,00 \\
\hline
\end{tabular}

Fonte: GUERRA, 2012.

Como é possível observar na Tabela 4, o rendimento do coletor solar não convencional confeccionado e analisado possui um rendimento médio de $15 \%$, e conforme já foi mencionado, esse valor é consideravelmente inferior aos valores médios de outros coletores solares não convencionais, os quais têm um rendimento médio entre 30 e $35 \%$. Esse baixo rendimento já era esperado devido à ausência da cobertura transparente dentre os itens presentes na composição do coletor solar não convencional, que minimizaria as trocas por conveç̧ão e radiação com o meio ambiente.

Apesar do baixo rendimento térmico, o coletor solar em estudo foi capaz de atingir ao final de todos os dias, níveis de temperatura entre $6,0^{\circ} \mathrm{C}$ e $13,0^{\circ} \mathrm{C}$ superior à média de $36^{\circ} \mathrm{C}$, que de acordo com Reis (2009), é a ideal para o banho. Desta forma, o sistema mostra que em apenas um dia de funcionamento é capaz de aquecer até que seu objetivo seja atingido, embora apresente baixa eficiência térmica quando comparado aos coletores convencionais comercializados no mercado.

Quanto à radiação solar global registrada nos dias de estudo, apesar da nebulosidade existente em alguns horários do primeiro dia de ensaio, observou-se que a radiação solar global para todos os dias de ensaio esteve em torno de $1000 \mathrm{~W} / \mathrm{m}^{2}$, demonstrando que os dias selecionados para realização dos ensaios apresentaram condições solarimétricas próximas. 
Concluído os resultados que determinam o rendimento térmico do coletor solar em questão, é mostrado tanto o coeficiente global de perdas do coletor solar em estudo, como os parâmetros térmicos que foram utilizados para determinar esse coeficiente.

\subsection{RESULTADOS DOS PARÂMETROS TÉRMICOS PARA DETERMINAÇÃO DO COEFICIENTE GLOBAL DE PERDAS DO COLETOR SOLAR NÃO CONVENCIONAL E DE BAIXO CUSTO EM ESTUDO}

Para o cálculo do coeficiente global de perdas do coletor solar estudado, é necessário determinar a temperatura média da placa absorvedora, que no caso obteve suas medições no decorrer das três horas consideradas aquelas com maior índice de radiação solar, ou seja, entre às 11:00 e 13:00 horas.

As Figuras 18, 19 e 20 mostram os valores médios medidos em cada hora do primeiro, segundo e terceiro dias, respectivamente, bem como a temperatura média da grade absorvedora no final de cada hora.

No decorrer dos três dias de estudo, as temperaturas médias da placa absorvedora ( $\left.T_{M P}\right)$ estiveram entre $45,0^{\circ} \mathrm{C}$ e $55,6^{\circ} \mathrm{C}$. Esses valores de temperatura contribuem para a determinação da perda térmica do coletor solar a partir do coeficiente global de perdas.

Para o cálculo do coeficiente global de perdas (ULOSS) foi necessário utilizar os valores da diferença entre as temperaturas de entrada e saída do coletor solar em análise $(\Delta T)$, assim como os valores de radiação solar (ICOLETOR) e a potência útil transferida ao fluido de trabalho (Pu). Todas estas informações foram extraídas das Tabelas 1, 2 e 3, no intervalo de 11:00h às 13:00h.

\begin{tabular}{|c|c|c|c|c|c|}
\cline { 2 - 5 } \multicolumn{1}{c|}{} & $\mathbf{1 2}^{\circ}$ & $\mathbf{9}^{\circ}$ & $\mathbf{5}^{\circ}$ & $1^{\circ}$ & \multirow{2}{*}{ MÉDIAS } \\
\cline { 2 - 5 } \multicolumn{1}{c|}{} & & & & & 43,8 \\
\hline TUBO & 40,0 & 44,0 & 47,0 & 44,0 & \\
\hline ALETA & 55,0 & 61,0 & 56,0 & 41,0 & 53,3 \\
\hline & & & & & \\
\hline TUBO & 41,0 & 42,0 & 41,0 & 41,0 & 41,3 \\
\hline ALETA & 46,0 & 44,0 & 45,0 & 45,0 & 45,0 \\
\hline & & & & & \\
\hline TUBO & 44,0 & 39,0 & 39,0 & 41,0 & 40,8 \\
\hline ALETA & 47,0 & 54,0 & 47,0 & 36,0 & 46,0 \\
\hline
\end{tabular}

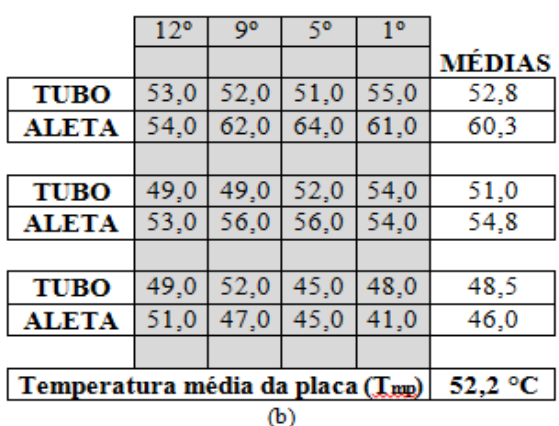

\begin{tabular}{|c|c|c|c|c|c|}
\hline & $12^{\circ}$ & $9^{\circ}$ & $5^{\circ}$ & $1^{\circ}$ & \multirow[b]{2}{*}{ MÉDIAS } \\
\hline & & & & & \\
\hline TUBO & 45,0 & 44,0 & 45,0 & 44,0 & 44,5 \\
\hline ALETA & 45,0 & 45,0 & 44,0 & 46,0 & 45,0 \\
\hline TUBO & 46,0 & 46,0 & 45,0 & 45,0 & 45,5 \\
\hline ALETA & 46,0 & 47,0 & 55,0 & 61,0 & 52,3 \\
\hline TUBO & 39,0 & 39,0 & 40,0 & 41,0 & 39,8 \\
\hline ALETA & 52,0 & 54,0 & 50,0 & 51,0 & 51,8 \\
\hline \multicolumn{5}{|c|}{ Temperatura média da placa $\left(T_{m p}\right)$} & $46,5^{\circ} \mathrm{C}$ \\
\hline
\end{tabular}

Figura 1810 - Temperatura média, em graus ${ }^{\circ} \mathrm{C}$, em diversos pontos da superfície da grade absorvedora às (a) 11:00h, (b) 12:00h e (c) 13:00h, todas do primeiro dia de ensaio $(01 / 06 / 2012)$

Fonte: GUERRA, 2012 

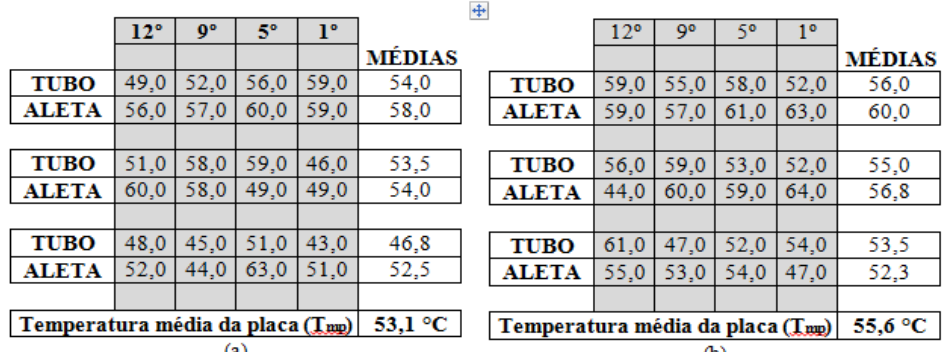

\begin{tabular}{|c|c|c|c|c|c|}
\hline & $12^{\circ}$ & $9^{\circ}$ & $5^{\circ}$ & $1^{\circ}$ & \multirow[b]{2}{*}{ MÉDIAS } \\
\hline & & & & & \\
\hline TUBO & 50,0 & 58,0 & 56,0 & 58,0 & 55,5 \\
\hline ALETA & 55,0 & 58,0 & 66,0 & 59,0 & 59,5 \\
\hline TUBO & 53,0 & 52,0 & 53,0 & 47,0 & 51,3 \\
\hline ALETA & 57,0 & 54,0 & 51,0 & 53,0 & 53,8 \\
\hline TUBO & 53,0 & 46,0 & 48,0 & 54,0 & 50,3 \\
\hline ALETA & 56,0 & 50,0 & 46,0 & 46,0 & 49,5 \\
\hline Tempera & a $n$ & lia da & plac & $\left(T_{\text {mp }}\right)$ & $53,3^{\circ} \mathrm{C}$ \\
\hline
\end{tabular}

Figura 19 - Temperatura média, em graus ${ }^{\circ} \mathrm{C}$, em diversos pontos da superfície da grade absorvedora às (a) 11:00h, (b) 12:00h e (c) 13:00h, todas do segundo dia de ensaio (04/06/2012).

Fonte: GUERRA, 2012
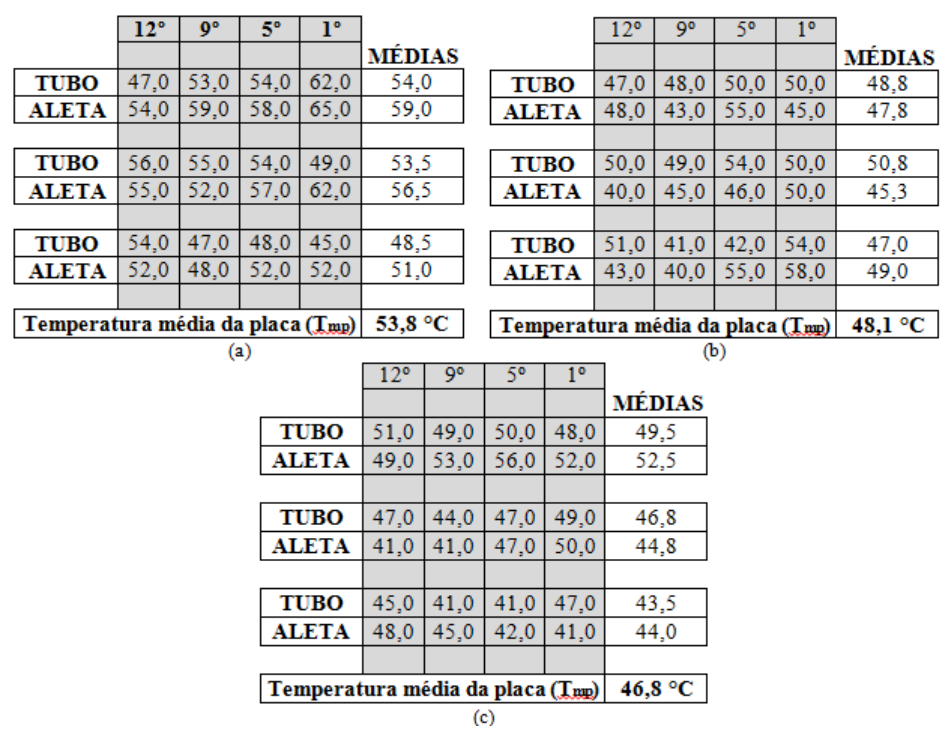

Figura 20 - Temperatura média, em graus ${ }^{\circ} \mathrm{C}$, em diversos pontos da superfície da grade absorvedora às (a) 11:00h, (b) 12:00h e (c) 13:00h, todas do terceiro dia de ensaio (05/06/2012).

Fonte: GUERRA, 2012

Além disso, como pode ser observado nas Tabelas 5, 6 e 7, foi necessário ainda determinar a temperatura ambiente $\left(\mathrm{T}_{\mathrm{AMB}}\right)$; calcular a potência absorvida pelo coletor $\left(\mathrm{P}_{\mathrm{abs}}\right)$; e a potência perdida pelo coletor $\left(\mathrm{P}_{\mathrm{P}}\right)$.

Tabela 5 - Dados que determinam o coeficiente global de perdas no primeiro dia de ensaio (01/06/2012).

\begin{tabular}{ccccccccc}
\hline $\begin{array}{c}\text { TEMPO } \\
(\mathbf{h})\end{array}$ & $\mathbf{\Delta T}\left({ }^{\circ} \mathbf{C}\right)$ & $\begin{array}{c}\text { Icoletor } \\
\left(\mathbf{k W} / \mathbf{m}^{\mathbf{2}}\right)\end{array}$ & Tamb $\left({ }^{\circ} \mathbf{C}\right)$ & $\begin{array}{c}\text { Pabs } \\
(\mathbf{k W})\end{array}$ & $\begin{array}{c}\mathbf{P u} \\
(\mathbf{k W})\end{array}$ & $\begin{array}{c}\mathbf{P p} \\
(\mathbf{k W})\end{array}$ & $\begin{array}{c}\text { Uloss } \\
\left(\mathbf{k W} / \mathbf{m}^{\mathbf{2}} \mathbf{K}\right)\end{array}$ & $\begin{array}{c}\text { Uloss } \\
\left(\mathbf{W} / \mathbf{m}^{\mathbf{2}} \mathbf{K}\right)\end{array}$ \\
\hline $\mathbf{1 1 : 0 0}$ & 17,00 & 1,47 & 37,90 & 2,35 & 0,34 & 2,01 & 0,14 & 141,35 \\
$\mathbf{1 2 : 0 0}$ & 16,00 & 1,35 & 43,70 & 2,16 & 0,32 & 1,84 & 0,11 & 108,41 \\
$\mathbf{1 3 : 0 0}$ & 12,00 & 0,79 & 38,00 & 1,26 & 0,24 & 1,02 & 0,06 & 60,46 \\
\hline Média & $\mathbf{1 5 , 0 0}$ & $\mathbf{1 , 2 0}$ & $\mathbf{3 9 , 8 7}$ & $\mathbf{1 , 9 2}$ & $\mathbf{0 , 3 0}$ & $\mathbf{1 , 6 2}$ & $\mathbf{0 , 1 0}$ & $\mathbf{1 0 3 , 4 1}$ \\
\hline
\end{tabular}

Fonte: GUERRA, 2012. 
Tabela 6 - Dados que determinam o coeficiente global de perdas no segundo dia de ensaio (04/06/2012)

\begin{tabular}{|c|c|c|c|c|c|c|c|c|}
\hline $\begin{array}{c}\text { TEMPO } \\
\text { (h) }\end{array}$ & $\Delta \mathrm{T}\left({ }^{\circ} \mathrm{C}\right)$ & $\begin{array}{l}\text { Icoletor } \\
\left(\mathrm{kW} / \mathrm{m}^{2}\right)\end{array}$ & $\begin{array}{c}\text { Tamb } \\
\left({ }^{\circ} \mathrm{C}\right)\end{array}$ & Pabs (kW) & $\mathrm{Pu}(\mathrm{kW})$ & $\mathrm{Pp}(\mathrm{kW})$ & $\begin{array}{c}\text { Uloss } \\
\left(\mathrm{kW} / \mathrm{m}^{2} \mathrm{~K}\right)\end{array}$ & $\begin{array}{c}\text { Uloss } \\
\left(\mathrm{W} / \mathrm{m}^{2} \mathrm{~K}\right)\end{array}$ \\
\hline $11: 00$ & 15,0 & 1,400 & 42,1 & 2,24 & 0,30 & 1,94 & 0,0880 & 88,0 \\
\hline $12: 00$ & 17,0 & 1,301 & 44,3 & 2,08 & 0,34 & 1,74 & 0,0772 & 77,2 \\
\hline $13: 00$ & 16,0 & 1,182 & 46,3 & 1,89 & 0,32 & 1,57 & 0,1125 & 112,5 \\
\hline Média & 16,00 & 1,29 & 44,23 & 2,07 & 0,32 & 1,75 & 0,09 & 92,59 \\
\hline
\end{tabular}

Fonte: GUERRA, 2012.

Tabela 7 - Dados que determinam o coeficiente global de perdas no terceiro dia de ensaio (05/06/2012)

\begin{tabular}{ccccccccc}
\hline $\begin{array}{c}\text { TEMPO } \\
(\mathbf{h})\end{array}$ & $\begin{array}{c}\boldsymbol{\Delta} \mathbf{T} \\
\left({ }^{\circ} \mathbf{C}\right)\end{array}$ & $\begin{array}{c}\text { Icoletor } \\
\left(\mathbf{k W} / \mathbf{m}^{\mathbf{2}}\right)\end{array}$ & $\begin{array}{c}\text { Tamb } \\
\left({ }^{\circ} \mathbf{C}\right)\end{array}$ & Pabs $(\mathbf{k W})$ & Pu (kW) & Pp (kW) & $\begin{array}{c}\text { Ulos } \\
\left(\mathbf{k W} / \mathbf{m}^{\mathbf{2}} \mathbf{K}\right)\end{array}$ & $\begin{array}{c}\text { Uloss } \\
\left(\mathbf{W} / \mathbf{m}^{\mathbf{2}} \mathbf{K}\right)\end{array}$ \\
\hline $\mathbf{1 1 : 0 0}$ & 22,0 & 1,281 & 41,5 & 2,05 & 0,44 & 1,61 & 0,0658 & 65,8 \\
$\mathbf{1 2 : 0 0}$ & 17,0 & 1,168 & 36,9 & 1,87 & 0,34 & 1,53 & 0,0684 & 68,4 \\
$\mathbf{1 3 : 0 0}$ & 15,0 & 1,290 & 41,5 & 2,06 & 0,30 & 1,77 & 0,1655 & 165,5 \\
\hline Média & $\mathbf{1 8 , 0 0}$ & $\mathbf{1 , 2 4 6}$ & $\mathbf{3 9 , 9 7}$ & $\mathbf{1 , 9 9}$ & $\mathbf{0 , 3 6}$ & $\mathbf{1 , 6 4}$ & $\mathbf{0 , 1 0}$ & $\mathbf{9 9 , 9 1}$ \\
\hline
\end{tabular}

Fonte: GUERRA, 2012.

Para efetuar o cálculo da potência absorvida pelo coletor $\left(P_{A B S}\right)$; da potência perdida pelo coletor ( $\mathrm{P}_{\mathrm{P}}$ ); e do coeficiente global de perdas ( $\mathrm{U}_{\text {Loss }}$ ) das Tabelas 5, 6 e 7, foram consideradas as seguintes constantes: área do coletor solar plano não convencional e de baixo custo (A) sendo, no caso, $2 \mathrm{~m}^{2}$; a vazão mássica (m) de $0,004762 \mathrm{~kg} / \mathrm{s}$; o calor específico de $4,18 \mathrm{~kJ} / \mathrm{kg}$. ${ }^{\circ} \mathrm{C}$; e, por fim, a absortividade da placa $\left(\alpha_{\mathrm{P}}\right)$.Como se trata de uma placa com pintura preto fosco, considera-se 0,8 , de acordo com o que foi afirmado por Bezerra (2001).

A Tabela 8 mostra, em resumo, os valores médios dos coeficientes globais de perdas para cada dia de estudo, bem como a média total do coeficiente global de perdas térmica calculada ao término dos três dias de estudos.

Tabela 8 - Resultado médio geral do coeficiente global de perdas do coletor solar não convencional e de baixo custo

\begin{tabular}{ccc}
\hline Dias de Ensaio & Uloss $\left(\mathbf{k W} / \mathbf{m}^{2} \mathbf{K}\right)$ & Uloss $\left(\mathbf{W} / \mathbf{m}^{2} \mathbf{K}\right)$ \\
\hline DIA 1 & 0,10 & 103,41 \\
DIA 2 & 0,09 & 92,59 \\
DIA 3 & 0,10 & 99,91 \\
\hline Média & $\mathbf{0 , 0 9 6 6 7}$ & $\mathbf{9 8 , 6 3 6 7}$ \\
\hline
\end{tabular}

Fonte: GUERRA, 2012.

Ainda na Tabela 8, é evidenciado o coeficiente global de perdas térmicas do coletor solar não convencional e de baixo custo que é bastante elevado e superior aos coletores convencionais existentes no mercado, que, de acordo com o afirmado por Souza (2002) apud Lopo (2010), está entre 6,0 e $12,0 \mathrm{~W} / \mathrm{m}^{2}$.K. Vale ressaltar que esses são valores esperados, uma vez que o coletor em estudo não possui cobertura transparente e isolamento adequado, como já supracitado, de 
maneira que seja capaz de tornar irrisórias as trocas convectivas entre o coletor em estudo e o ambiente.

Finalizado os itens 5.1, 5.2 e 5.3, os quais têm como foco de estudo o coletor solar não convencional e de baixo custo, é necessário iniciar as análises dos reservatórios térmicos não convencionais e também de baixo custo.

5.4 RESULTADOS DO COMPORTAMENTO DA TEMPERATURA DA ÁGUA NO RESERVATÓRIO TERMICO NÃO CONVENCIONAL E DE BAIXO CUSTO EM ESTUDO

O estudo realizado no reservatório térmico proposto ocorre através dos resultados médios gerais, bem como através do comportamento assumido pela temperatura da água em diversos pontos no interior do objeto de estudo, ou seja, do reservatório térmico não convencional e de baixo custo.

Os gráficos das Figuras 21, 22 e 23 mostram os níveis de temperatura média da água nos diferentes pontos do interior do reservatório térmico em estudo para cada dia de análise e para cada hora dentro do intervalo de funcionamento do sistema de aquecimento solar térmico, que no caso, esta compreendida entre às 8:00 e 15:00 horas.

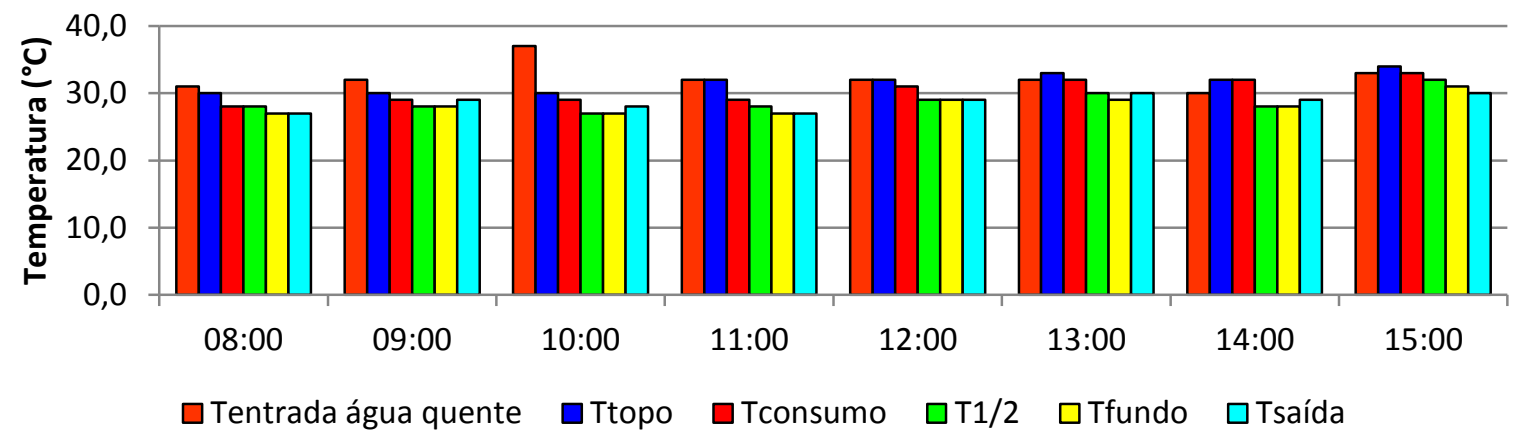

Figura 2111 - Comparação entre as temperaturas médias horárias no interior do reservatório térmico no primeiro dia de estudo (01/06/2012).

Fonte: GUERRA, 2012

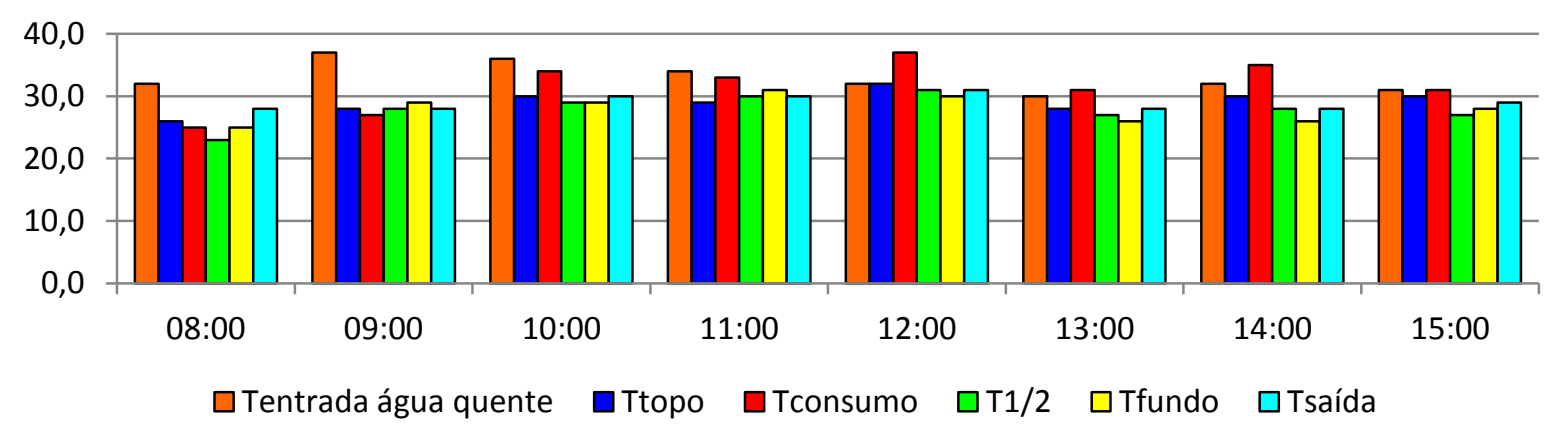

Figura 22 - Comparação entre as temperaturas médias horárias no interior do reservatório térmico no segundo dia de estudo (04/06/2012).

Fonte: GUERRA, 2012 


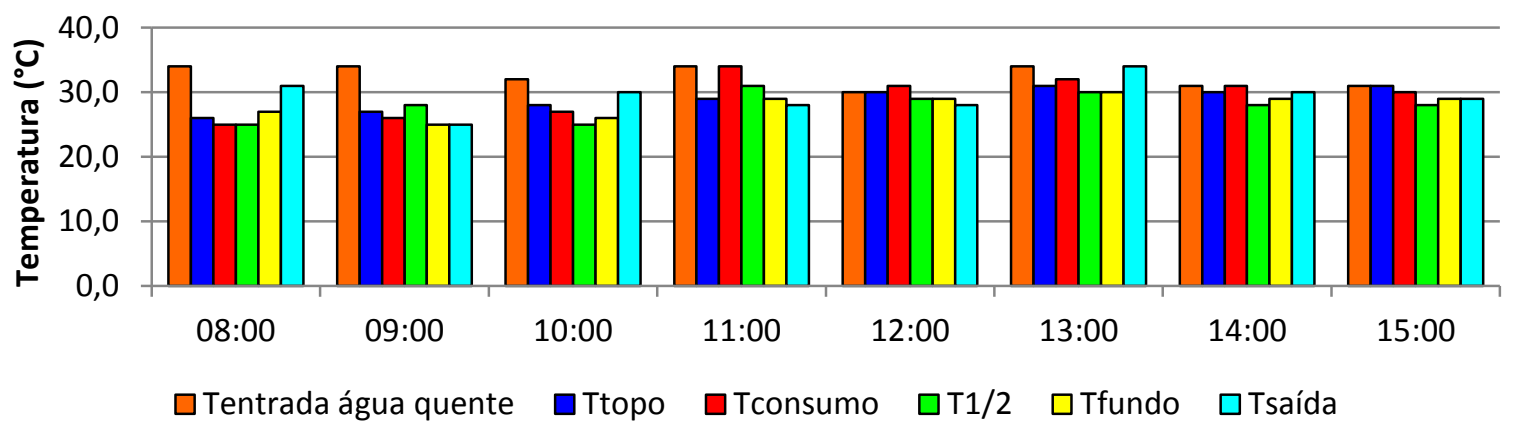

Figura 2312 - Comparação entre as temperaturas médias horárias no interior do reservatório térmico no terceiro dia de estudo (05/06/2012)

Fonte: GUERRA, 2012

Os gráficos das Figuras 21, 22 e 23 mostram a uniformidade presente no interior do reservatório quando são visualizados os níveis de temperatura tanto do topo, como do fundo do reservatório térmico. Entretanto, para efetivar essa comprovação, será mostrado o cálculo da diferença percentual dessas temperaturas após a exibição da Tabela 9. A Tabela 9 resume os dados exibidos graficamente nas Figuras 21, 22 e 23, apresentando os níveis de temperatura da água aquecida em vários pontos do reservatório térmico para os três dias de ensaio.

Tabela 9 - Níveis de temperatura média em vários pontos do reservatório térmico para cada dia de ensaio

\begin{tabular}{ccccccc}
\hline TEMPO (h) & Tentrada água quente & Ttopo & Tconsumo & T1/2 & Tfundo & Tsaída \\
\hline Dia 1 & 32,4 & 31,6 & 30,4 & 28,8 & 28,3 & 28,6 \\
Dia 2 & 33,0 & 29,1 & 31,6 & 27,9 & 28,0 & 29,0 \\
Dia 3 & 32,5 & 29,0 & 29,5 & 28,0 & 28,0 & 29,4 \\
Média & 32,6 & 29,9 & 30,5 & 28,2 & 28,1 & 29,0 \\
\hline \multicolumn{5}{c}{} \\
\hline
\end{tabular}

Fonte: GUERRA, 2012.

O SASncbc proposto e aqui estudado, não proporciona um aquecimento de água no reservatório térmico adequado para banho, ou seja, o nível de temperatura da água não atinge $36,0^{\circ} \mathrm{C}$, considerado o nível médio de temperatura exigido para o banho.

Ainda analisando a Tabela 9, observa-se que a diferença entre o nível de temperatura mais elevado medido no topo do reservatório, e o menor verificado no fundo do reservatório em estudo, correspondeu a, aproximadamente, $11,4 \%$, ou seja, demonstrando que quase toda água contida no reservatório térmico esteve próximo à uniformidade desejada.

A proximidade com a uniformidade é evidenciada na Figura 24, a qual mostra os perfis das temperaturas médias no interior do reservatório em cada dia de análise. 


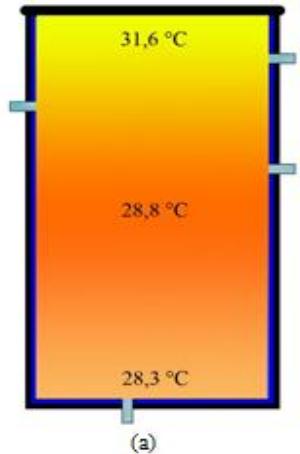

(a)

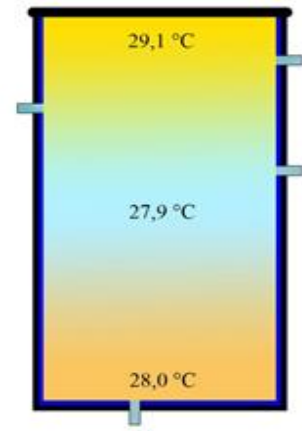

(b)

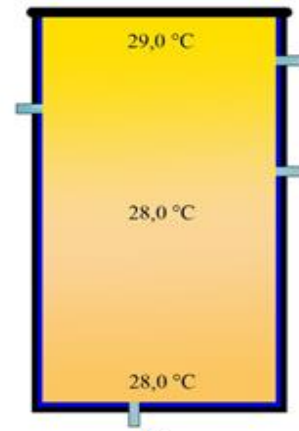

(c)

Figura 2413 - Média dos níveis de temperatura dentro do reservatório no (a) primeiro, (b) segundo e (c) terceiro dia de ensaio.

Fonte: GUERRA, 2012

Encerrado os estudos que avaliam o comportamento do reservatório térmico no decorrer do funcionamento do SASncbc, é fundamental avaliar também, as perdas térmicas sofridas por esse reservatório térmico, que serão abordadas no item 5.5.

\subsection{RESULTADOS DA PERDA TÉRMICA DO RESERVATÓRIO TÉRMICO NÃO CONVENCIONAL E DE BAIXO CUSTO EM ESTUDO}

Os resultados dos testes que avaliam as perdas térmicas suportadas pelo reservatório térmico em análise estão mostrados na Tabela 10 e no gráfico da Figura 25 , através da temperatura, em graus Celsius $\left({ }^{\circ} \mathrm{C}\right)$, do topo $\left(T_{\text {topo }}\right)$; meio $\left(T_{1 / 2}\right)$; fundo $\left(T_{\text {fundo }}\right)$; e de consumo ( $\left.T_{\text {consumo }}\right)$ do interior do reservatório térmico.

Tabela 10 - Resultados do teste de perda térmica realizado com o reservatório térmico

\begin{tabular}{cccccccc}
\hline \multirow{2}{*}{ TEMPO (h) } & \multirow{2}{*}{ Dia } & \multirow{I}{*}{$\left(\mathbf{W} / \mathbf{m}^{\mathbf{2}}\right)$} & \multirow{2}{*}{ Tamb $\left({ }^{\circ} \mathbf{C}\right)$} & & \multicolumn{3}{c}{ Reservatório } \\
\cline { 5 - 8 } & & & & Ttopo & T1/2 & Tconsumo & Tfundo \\
\hline $\mathbf{1 5 : 0 0}$ & $05 / 06 / 12$ & 725,0 & 31,9 & 31,0 & 28,0 & 30,0 & 29,0 \\
$\mathbf{0 7 : 0 0}$ & $06 / 06 / 12$ & 545,1 & 30,4 & 31,0 & 31,0 & 31,0 & 30,0 \\
$\mathbf{1 5 : 0 0}$ & $06 / 06 / 12$ & 811,0 & 35,8 & 36,0 & 30,0 & 34,0 & 30,0 \\
\hline
\end{tabular}

Fonte: GUERRA, 2012.

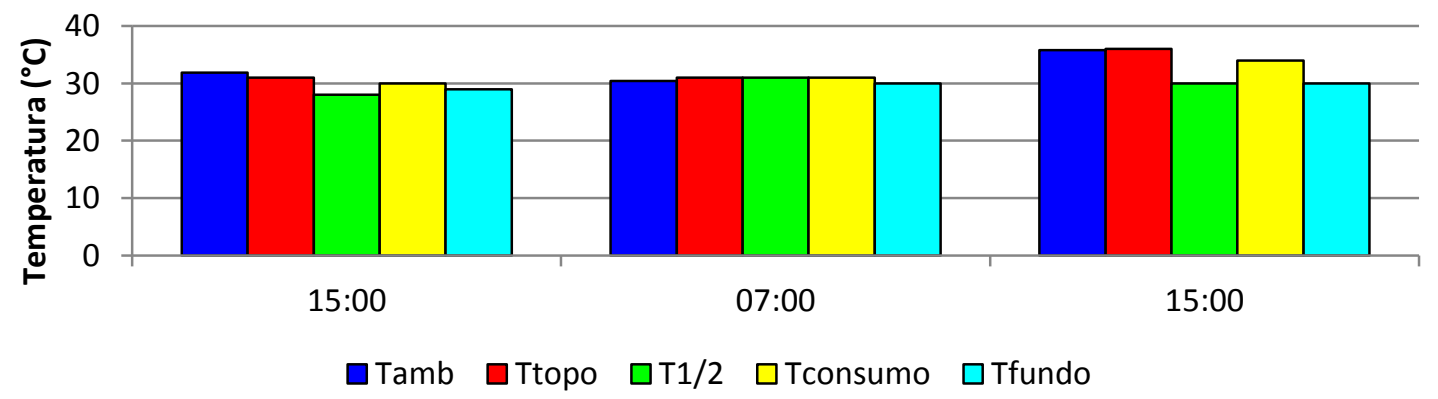

Figura 25 - Comparação entre os níveis de temperaturas médias no interior do reservatório após ser isolado do sistema

Fonte: GUERRA, 2012 
Ao observar os dados da Tabela 10 e o gráfico da Figura 28, conclui-se que o reservatório térmico não convencional e de baixo custo analisado tem uma significativa eficiência térmica, uma vez que no decorrer de 24 horas, conseguiu manter a temperatura média do seu interior, mesmo sem haver qualquer ligação entre o reservatório em estudo e o coletor solar que o alimenta com água quente, concluindo assim, a sua baixa perda térmica. É importante destacar também, que a eficiência do reservatório térmico em análise pode ser comparada com a eficiência dos reservatórios convencionais com preços normalmente bem mais elevados.

Além disso, no decorrer das 24 horas de análise após o desacoplamento entre o reservatório e coletor solar, foi observado que o reservatório em estudo apresentou aumento de temperatura e os melhores resultados no seu interior, após passar o dia sendo aquecido apenas pela radiação solar global absorvida por ele mesmo, provavelmente devido à pintura com tinta preto fosco do seu exterior. Isso mostra que as perdas mais significativas que o reservatório pode vir a sofrer são devido à tampa do reservatório térmico, já que essa foi a região que apresentou maior oscilação de níveis de temperatura devido aos níveis externos da temperatura.

Por fim, em relação à resistência mecânica do reservatório térmico em estudo, não foi apresentado qualquer dano à estrutura, ou seja, suportou o peso que equivale ao volume total de água contido no referido reservatório. Do mesmo modo, é possível afirmar que a vedação foi adequada, uma vez que não foi constatado qualquer vazamento tanto no reservatório térmico, como em todo o sistema de aquecimento.

Finalizadas as análises dos resultados obtidos com o SASncbc, o item 6 mostra as conclusões do estudo realizado, bem como algumas sugestões que poderão ser úteis a trabalhos futuros que sigam a mesma linha de pesquisa.

\section{CONCLUSÃO}

O coletor solar em estudo (sem cobertura transparente) apresentou bons índices de temperatura, entre $41^{\circ} \mathrm{C}$ e $67^{\circ} \mathrm{C}$. Seu rendimento térmico variou entre $6 \%$ e $31 \%$, que comparado a outros coletores alternativos e de baixo custo desenvolvidos por pesquisadores, que registram eficiência térmica em torno de 30 a $35 \%$, pode ser considerado um rendimento térmico baixo. Já os coletores solares convencionais comercializados no mercado nacional apresentam normalmente eficiência térmica superior a $55 \%$.

Também foi possível verificar que as perdas térmicas são superiores as de outros modelos de sistemas alternativos e de baixo custo já estudados, como também em relação as dos coletores convencionais. Porém, é válido lembrar que o coletor solar em estudo não tem cobertura transparente capaz de contribuir para um maior aquecimento e também para minimizar significativamente as trocas térmicas entre o coletor solar e o ambiente, contribuindo assim, para essa elevada perda térmica.

Um outro ponto analisado no presente trabalho refere-se à degradação por ultravioleta, que pode ser amenizada ao se utilizar a tinta preta fosca, que cobre toda a área da placa absorvedora, pois os pigmentos pretos são absorvedores de radiação ultravioleta. Entretanto, foi possível verificar que o tubo de PVC utilizado no coletor analisado neste estudo não é adequado para ser utilizado na cidade de Mossoró, pois tanto a água que passa no interior dos tubos PVC, como os próprios tubos de PVC, em alguns momentos, não só atingiram como ultrapassaram a 
temperatura de $60^{\circ} \mathrm{C}$, que é o nível crítico de temperatura que compromete a susceptibilidade para início de degradação térmica do PVC.

Desta forma, sugere-se a substituição e utilização de tubos de Cloreto de Povilina Clorado (CPVC), conforme é recomendado na NBR 7198. Esses tubos são específicos para serem utilizados em sistemas de água quente, pois suportam temperatura máxima até 80 으, assim, não comprometendo o sistema. Contudo, a utilização de tais tubos irá elevar o valor do sistema proposto, pois os mesmos são cerca de quatro vezes mais caros que os tubos de PVC utilizados no sistema em estudo.

Em relação ao reservatório térmico, o estudo apresentou um sistema de isolação bastante eficaz podendo ser comparado aos reservatórios térmicos convencionais, pois os níveis de temperatura atingidos no interior do reservatório térmico em estudo se mantiveram sempre próximos. Em relação à temperatura do fundo do tambor, essa esteve sempre próxima a de seu topo, apresentando uma variação máxima de 6으, demonstrando assim, uma boa taxa de aquecimento. Desta forma, é possível afirmar que esse é um reservatório térmico viável para serem utilizados em sistemas alternativos de aquecimento solar de água.

No que diz respeito aos baixos níveis de temperatura medidos no interior do reservatório, entre às médias de $28^{\circ} \mathrm{C}$ e $33^{\circ} \mathrm{C}$, esses podem ter sido ocasionados por problemas no termossifão, possivelmente causado pelo surgimento de bolhas no trajeto da água quente que saía do coletor solar e chegava ao interior do reservatório térmico, ou devido a perda de calor provocada pelo processo de "abertura e fechamento" da tampa do reservatório térmico a cada 1 hora, para que as medições pudessem ser realizadas, podendo causar perturbação da estratificação da água do interior do reservatório nos momentos das medições.

Para finalizar, após os estudos individuais realizados tanto no coletor solar quanto no reservatório térmico do sistema proposto, pode-se concluir que o objetivo do trabalho foi atingido, pois foi analisada a possibilidade de utilização e instalação de um sistema de aquecimento de água utilizando materiais alternativos e de baixo custo na cidade de Mossoró/RN, bem como o desempenho térmico deste sistema. O sistema mostrou-se de fácil fabricação e montagem, apresentando fácil manuseio. A configuração testada mostrou-se viável para o fim proposto, no caso, a obtenção de água quente destinada ao banho em nível correspondente a no mínimo $36^{\circ} \mathrm{C}$. Conforme supramencionado, o único problema identificado durante os ensaios realizados referese aos tubos de PVC utilizados no coletor solar, que não são adequados para o sistema instalado em Mossoró/RN por apresentar possibilidade de degradação devido às altas temperaturas atingidas, mas propõe-se a substituição de tal tubulação pelos tubos de CPVC, sendo este último mais adequado para temperaturas superiores a $60^{\circ} \mathrm{C}$.

\section{REFERÊNCIAS}

1. ABREU, R. F. Estudo térmico de um sistema solar de aquecimento de água residencial para duas configurações de superfície absorvedora. 2009. 71 f. Dissertação (Mestrado em Engenharia Mecânica) - Programa de Pós-Graduação em Engenharia Mecânica, Universidade Federal do Rio Grande do Norte, Natal-RN, 2009.

2. ALVES, R. B. de M. B. Energia Solar como fonte elétrica e de aquecimento no uso residencial. 2009. 75f. Monografia (Graduação em Engenharia Civil) - Universidade Anhembi Morumbi, São 
Paulo, 2009. Disponível em: <http://engenharia.anhembi.br/tcc-09/civil-39.pdf>. Acesso em: 15 maio 2011.

3. ASSOCIAÇÃO BRASILEIRA DE NORMAS TÉCNICAS. NBR 7198: Projeto e execução de instalações prediais de água quente. Ebah, Rio de Janeiro, set. 1993. Disponivel em: <http://www.ebah.com.br/content/ABAAAAi7EAl/nbr-7198>. Acesso em: 19 dez. 2011.

4. BEZERRA, A. M. Aplicações térmicas da energia solar. 4. ed. João Pessoa: Universitária, 2001, Cap. 2, p. 47-96.

5. FAE-UFPE; CEPEL: Atlas Solarimétrico do Brasil: Banco de dados terrestres. 1a ed. Recife, PE, $2000.111 p$ Disponível em: <http://www.cresesb.cepel.br/publicacoes/download/Atlas_Solarimetrico_do_Brasil_2000.p df>. Acesso em: 15 fev. 2012.

6. FANTINELLI, J. T. Análise da evolução de ações na difusão do aquecimento solar de água para habitações populares: Estudo de caso em Contagem - MG. 2006. 294f. Tese (Doutorado em Planejamento de Sistemas Energéticos) - Faculdade de Engenharia Mecânica, Universidade Estadual de Campinas-SP, 2006.

7. GOMES, M. R. Projeto, construção e análise de eficiência térmica de dois sistemas de aquecimento solar de água de baixo custo. 2010. 94f. Dissertação (Mestrado em Engenharia Mecânica) - Programa de Pós-Graduação em Engenharia Mecânica, Universidade Federal do Rio Grande do Norte, Natal-RN, 2010.

8. GUERRA, M. I.S. Análise do desempenho térmico de um sistema de aquecimento solar de baixo custo na cidade de Mossoró - RN. 2012. 98 f. Monografia - Graduação em Engenharia de Energia, Universidade Federal Rural do Semi-Árido, Mossoró-RN, 2012.LEITÃO, M. M. V. B. R.; et al. Balanço de Radiação Sobre um Solo Descoberto para quatro Períodos do Ano. Revista de Ciência \& Tecnologia, ano 2000, n. 15, p 59-66. Disponível em: <http://www.unimep.br/phpg/editora/revistaspdf/rct15art07.pdf>. Acesso em: 13 mar 2012.

9. LOPO, A. B. Análise do desempenho térmico de um sistema de aquecimento solar de baixo custo. 2010. 82 f. Dissertação (Mestrado em Engenharia Mecânica) - Programa de PósGraduação em Engenharia Mecânica, Universidade Federal do Rio Grande do Norte, Natal-RN, 2010.

10. PEREIRA, E. B.; et al. Atlas Brasileiro de Energia Solar. 1. Ed. São José dos Campos: Swera, 2006,60p.

11. REIS, E. P. Análise do desempenho térmico de um sistema de aquecimento solar utilizando coletor com superfície absorvedora em chapas de forro de PVC. 2009. 85 f. Dissertação (Mestrado em Engenharia Mecânica) - Programa de Pós-Graduação em Engenharia Mecânica, Universidade Federal do Rio Grande do Norte, Natal-RN, 2009.

12. SANTOS, N. R. G. Projeto, construção e análise de desempenho de coletores solares alternativos utilizando garrafas pet. 2007. 100f. Dissertação (Mestrado em Engenharia Mecânica) - Programa de Pós-Graduação em Engenharia Mecânica, Universidade Federal do Rio Grande do Norte, Natal-Rn, 2007.

13. SAUER et al. Energias renováveis: ações e perspectivas na Petrobras. Bahia Análise \& Dados. Salvador, n.1 $\quad$ p. $9-22, \quad 2006.2$ Disponível em: <http://www.moretti.agrarias.ufpr.br/eletrificacao_rural/tc_02.pdf>. Acesso em: 05 set. 2012. 
14. SOCIEDADE DO SOL: Apresentação. São Paulo, 2003. Disponível em: <http://www.sociedadedosol.org.br/>. Acesso em: 1 fev 2012.

15. SOUZA, G. M.; SANTOS, N. R. G.; FÉLIX, L. F. Sistema de aquecimento solar utilizando elementos recicláveis. In: CONGRESSO BRASILEIRO DE ENERGIA SOLAR, 2, CONFERÊNCIA LATINOAMERICANA DE LA ISES, 3., 2008, Florianopolis. Anais... Florianópolis: CBENS ISES-CLA, 2008.

16. VARELLA, F. K. D. O. M. Tecnologia Solar Residencial: Inserção de aquecedores solares de água no distrito de Barão Geraldo - Campinas. 2004. 117f. Dissertação (Mestrado em Planejamento de Sistemas Energéticos) - Faculdade de Engenharia Mecânica, Universidade Estadual de Campinas, 2004. 